\title{
Development and testing of fish-retention devices for pots: transparent triggers significantly increase catch efficiency for Atlantic cod (Gadus morhua)
}

Chladek, Jérôme; Stepputtis, Daniel; Hermann, Andreas; Ljungberg, Peter; Rodriguez-Tress, Paco; Santos, Juan; Svendsen, Jon Christian

\author{
Published in: \\ ICES Journal of Marine Science
}

Link to article, DOI:

10.1093/icesjms/fsaa214

Publication date:

2021

Document Version

Peer reviewed version

Link back to DTU Orbit

Citation (APA):

Chladek, J., Stepputtis, D., Hermann, A., Ljungberg, P., Rodriguez-Tress, P., Santos, J., \& Svendsen, J. C. (2021). Development and testing of fish-retention devices for pots: transparent triggers significantly increase catch efficiency for Atlantic cod (Gadus morhua). ICES Journal of Marine Science, 78(1), 199-219. [fsaa214]. https://doi.org/10.1093/icesjms/fsaa214

\section{General rights}

Copyright and moral rights for the publications made accessible in the public portal are retained by the authors and/or other copyright owners and it is a condition of accessing publications that users recognise and abide by the legal requirements associated with these rights.

- Users may download and print one copy of any publication from the public portal for the purpose of private study or research.

- You may not further distribute the material or use it for any profit-making activity or commercial gain

- You may freely distribute the URL identifying the publication in the public portal 


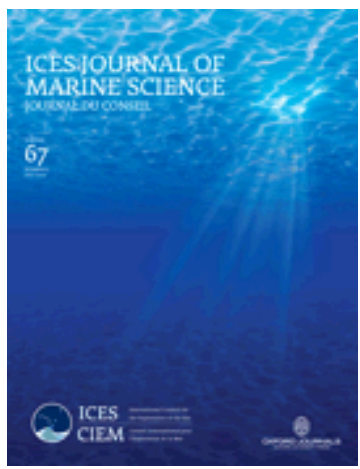

\section{Development and testing of fish-retention devices for pots: Transparent triggers significantly increase catch efficiency for Atlantic cod (Gadus morhua)}

\begin{tabular}{|c|c|}
\hline Journal: & ICES Journal of Marine Science \\
\hline Manuscript ID & ICESJMS-2020-373 \\
\hline Manuscript Types: & Original Article \\
\hline $\begin{array}{r}\text { Date Submitted by the } \\
\text { Author: }\end{array}$ & 02-Jul-2020 \\
\hline Complete List of Authors: & $\begin{array}{l}\text { Chladek, Jérôme; Johann Heinrich von Thünen-Institut Institut für } \\
\text { Ostseefischerei, Fisheries and Survey Technology } \\
\text { Stepputtis, Daniel; Thünen-Institute of Baltic Sea Fisheries, Alter Hafen } \\
\text { Süd 2, 18069 Rostock, Germany } \\
\text { Hermann, Andreas; Johann Heinrich von Thünen-Institut Institut für } \\
\text { Ostseefischerei, Fisheries and Survey Technology } \\
\text { Ljungberg, Peter; Sveriges lantbruksuniversitet Institutionen for } \\
\text { akvatiska resurser, Coastal laboratory } \\
\text { Rodriguez-Tress, Paco; Johann Heinrich von Thünen-Institut Institut für } \\
\text { Ostseefischerei } \\
\text { Santos, Juan; Thünen-Institute of Baltic Sea Fisheries, Fishing and } \\
\text { survey technology } \\
\text { Svendsen, Jon; Fisheries and Maritime Museum, ; University of Porto, } \\
\text { Interdisciplinary Centre of Marine and Environmental Research }\end{array}$ \\
\hline Keyword: & $\begin{array}{l}\text { passive fishing gear, fish pots, fish-retention device (FRD), triggers, fish- } \\
\text { gear interaction, Atlantic cod }\end{array}$ \\
\hline
\end{tabular}

\section{SCHOLARONE" Manuscripts}


Development and testing of fishretention devices for pots:

Transparent triggers significantly increase catch efficiency for Atlantic cod (Gadus morhua)

Jérôme Chladek ${ }^{1}$, Daniel Stepputtis ${ }^{1}$, Andreas Hermann ${ }^{1}$, Peter Ljungberg ${ }^{2}$, Paco Rodriguez-Tress ${ }^{1}$, Juan Santos ${ }^{1}$, Jon Christian Svendsen ${ }^{3}$

${ }^{1}$ Thünen Institute of Baltic Sea Fisheries, Alter Hafen Süd 2, 18069 Rostock, Germany

${ }^{2}$ Institute of Coastal Research, Department of Aquatic Resources, Swedish University of Agricultural Sciences, Kustlaboratoriet, Turistgatan 5, 45330 Lysekil, Sweden

${ }^{3}$ Technical University of Denmark, National Institute of Aquatic Resources (DTU Aqua), DK-2800 Lyngb^y, Denmark

*Corresponding author. Email: chladek-sc@posteo.de

Keywords: passive fishing gear, fish pots, fish-retention device (FRD), triggers, fish-gear interaction, Atlantic cod 
Fish pots have lower catch efficiency than gillnets and trawls, and therefore are rarely used for Atlantic cod (Gadus morhua) and similar species. Fish-retention devices (FRD), non-return devices that permit fish to enter the pot while impeding exit, reduce the pot exit rate and therefore can increase catches. Conventional FRDs, however, also reduce entry rate and may not improve catches. To increase pot-catch efficiency, we developed and tested a new trigger-type FRD, made of transparent acrylic glass, which we named acrylic fingers (AFs). AFs are almost invisible underwater and offer little resistance to entering cod. We compared AFs with Neptune fingers (NFs), a conventional trigger-type FRD with a distinct visual outline, by observing cod entry and exit rates through both trigger types rigged to a pot in a net pen. Both trigger types significantly reduced exit rates compared with a funnel without triggers; however, NFs also reduced entry rates by visually deterring cod. Specifically, AFs have higher entry-to-exit ratios and therefore improve catch efficiency. Combining AFs with funnels further increased catch efficiency. Thus, transparent acrylic triggers present a promising new approach to increasing pot-catch efficiency and may increase uptake of the cod-pot, an environmentally low-impact gear.

\section{Introduction}

Fishing affects marine ecosystems in many ways, including overfishing, impacts on the benthic environment, bycatch, and ghost fishing through lost or discarded fishing gear (e.g. Gilman et al., 2005, 2006; Suuronen et al., 2012; Žydelis et al., 2013; Grabowski et al., 2014; Lewison et al., 2014; Gilman, 2015). Fish pots are relatively small, easily transported, and typically boxlike fishing gears that have several advantages over other gear types. Fish pots have a comparatively small environmental impact (Thomsen et al., 2010; Shester and Micheli, 2011; Suuronen et al., 2012; Grabowski et al., 2014), an easily adjustable target-species size selectivity (Ovegård et al., 2011), and they deliver the catch alive and so in prime quality (Furevik, 1994; Thomsen et al., 2010; Suuronen et al., 2012; Humborstad et al., 2016). Therefore, increasing gear switch towards pots could reduce fishery-related environmental impacts and thus contribute to such objectives as ensuring sustainability of fisheries, as set out in Goal 14 of the United Nation's Sustainable Development Goals (UN, 2015), or more specifically in the European Common Fisheries Policy's Basic Regulation (EP and EU Council, 2013). To date, low pot-catch efficiency for many fish species, e.g. Atlantic cod, limits the use of fish pots in most fisheries (Furevik and Hågensen, 1997; Suuronen et al., 2012; Anders et al., 2017; Jørgensen et al., 2017; Meintzer et al., 2018). To increase the use of fish pots, their catch efficiency must be improved. Efficiency depends greatly on the pot entry and exit ratios, which are influenced in turn by the entrance design. An approach to reducing exits involves equipping pot entrances with fish-retention devices (FRDs; e.g. Carlile et al., 1997). One type of FRD has semi-rigid, finger-like structures made of metal or plastic, so-called triggers. Fish coming from outside can push inside with little effort, but not vice versa, because the fingers impede the exit. Triggers are used in Atlantic cod pot fishing in Newfoundland (Meintzer et al., 2018). Triggers were shown to increase the pot-catch rate up to 17-fold for Pacific cod (Gadus microcephalus; Carlile et al., 1997). Later studies of trigger-equipped pots in fisheries targeting Atlantic cod, however, have reported lower catch rates, with the observation that cod turn around towards the pot exterior right in front of the triggers (Olsen, 2014; Meintzer et al., 2017, 2018). This results in disproportionally fewer entries, resulting in reduced catch efficiency. All trigger types studied present a distinct visual outline to approaching cod. A recent study observing cod interaction with different entrance types in a net pen revealed increased cod passage rates (entry and exit) through transparent funnels, which apparently appear like a large unobstructed passage to approaching cod (Chladek et al., in prep.). This indicates that cod primarily use vision to assess an entrance. Lightweight transparent triggers offer little resistance to 
entering cod and are less perceptible or possibly imperceptible to the cod until they touch it. These qualities could harness the triggers' exit-blocking properties without decreasing entries.

In this study, we developed, assessed, and compared a new transparent trigger type with commercially available, non-transparent triggers. The transparent trigger FRD is made of transparent acrylic glass, which has a refractive index for visible light similar to seawater (Malitson, 1965; Austin and Halikas, 1976), making it almost invisible underwater. Also, because its density resembles seawater, an acrylic trigger finger can easily be pushed inwards by entering cod, offering little resistance. As conventional triggers, we tested 'Neptune fingers' (NF). They have been found to increase the pot-catch rate for Pacific cod (Carlile et al., 1997), but have not been evaluated for Atlantic cod. This study aimed to assess whether or not the transparent trigger FRDs and NFs improve Atlantic cod pot catch efficiency. Furthermore, we assessed whether or not the use of triggers renders funnels obsolete, or if a combination of the two elements improves fish-pot catch efficiency.

\section{Material and methods}

Experiments were conducted during April-May 2019 in the sporting marina of RostockWarnemünde, Germany (Figure appendix $1 ; 54^{\circ} 10^{\prime} 52.7^{\prime \prime} \mathrm{N} 12^{\circ} 05^{\prime} 18.0^{\prime \prime} \mathrm{E}$ ). Cod were caught off the coast of Rostock-Warnemünde, near the location of the experiments, using bottom trawl, fish pot, or hook and line. To minimize stress and exhaustion for the cod, fishing depths were always shallower than $20 \mathrm{~m}$ and trawl haul duration was limited to $30 \mathrm{~min}$. Cod were fed ad libitum with thawed and cut herring (Clupea harengus) once a week. Before experiments, cod were not fed for at least a week, because elevated hunger levels of fish often elevate motivation to enter fish pots (Thomsen et al., 2010; Ovegård et al., 2011, 2012; Ljungberg et al., 2016). Because the motivation of cod to enter pots is socially mediated (Anders et al., 2017), and because cod pots are usually encountered by more than one cod (e.g. Anders et al., 2016; Hedgärde et al., 2016; Ljungberg et al., 2016), groups of eight cod, or in one trial seven cod, were used in each trial. Because cod are cannibalistic (e.g. Hardie and Hutchings, 2011), and to avoid social stress, cod group in trials were kept in similar length ranges (30-39 cm, 40-49 cm, or 50-59 cm).

\section{Setup of the experiment}

Two identical net pens $\left(3 \times 3 \times 3 \mathrm{~m}=27 \mathrm{~m}^{3}\right.$; Mieske, 1998; see Figure appendix 2) were used, one for experimental treatments, the other for holding the fish before experiments. An experimental pot ( $\mathrm{W}$ $250 \mathrm{~cm} \times \mathrm{D} 140 \mathrm{~cm} \times \mathrm{H} 100 \mathrm{~cm}$ ) with two side-by-side entrances was constructed and positioned inside the net pen (Figure appendix 3 and 4). It was made of standard PVC tubes and green PE netting (Polyethylene, $25 \mathrm{~mm}$ bar length). Fish pot entrances were mounted on $(120 \times 100 \mathrm{~cm})$ PVC-tube frames and could be interchanged. We used a funnel as the baseline entrance type for indirect comparison of trigger performance (white PA (Polyamide) netting, $50 \mathrm{~cm}$ long, with a $60 \times 60 \mathrm{~cm}$ outer opening and a $20 \times 20 \mathrm{~cm}$ inner opening; Figure 1 upper part; Table 1; hereafter termed 'Fun' entrance). The funnel had $25 \mathrm{~mm}$ mesh bar lengths. The general design was based on the twochambered cod pot developed by Furevik et al. (2008) and used in several pot studies (e.g., Ovegård et al., 2011; Bryhn et al., 2014; Jørgensen et al., 2017).

Because the space available in the net pen was limited, we used a square opening design instead of the rectangular opening used by Furevik et al. (2008). To isolate the trigger effect from the funnel effect and to investigate if funnels are still needed when triggers are used, we also conducted experiments with the triggers attached to a simple $20 \times 20 \mathrm{~cm}$ opening in the pot net wall (Figure 1, lower part; Table 1). 

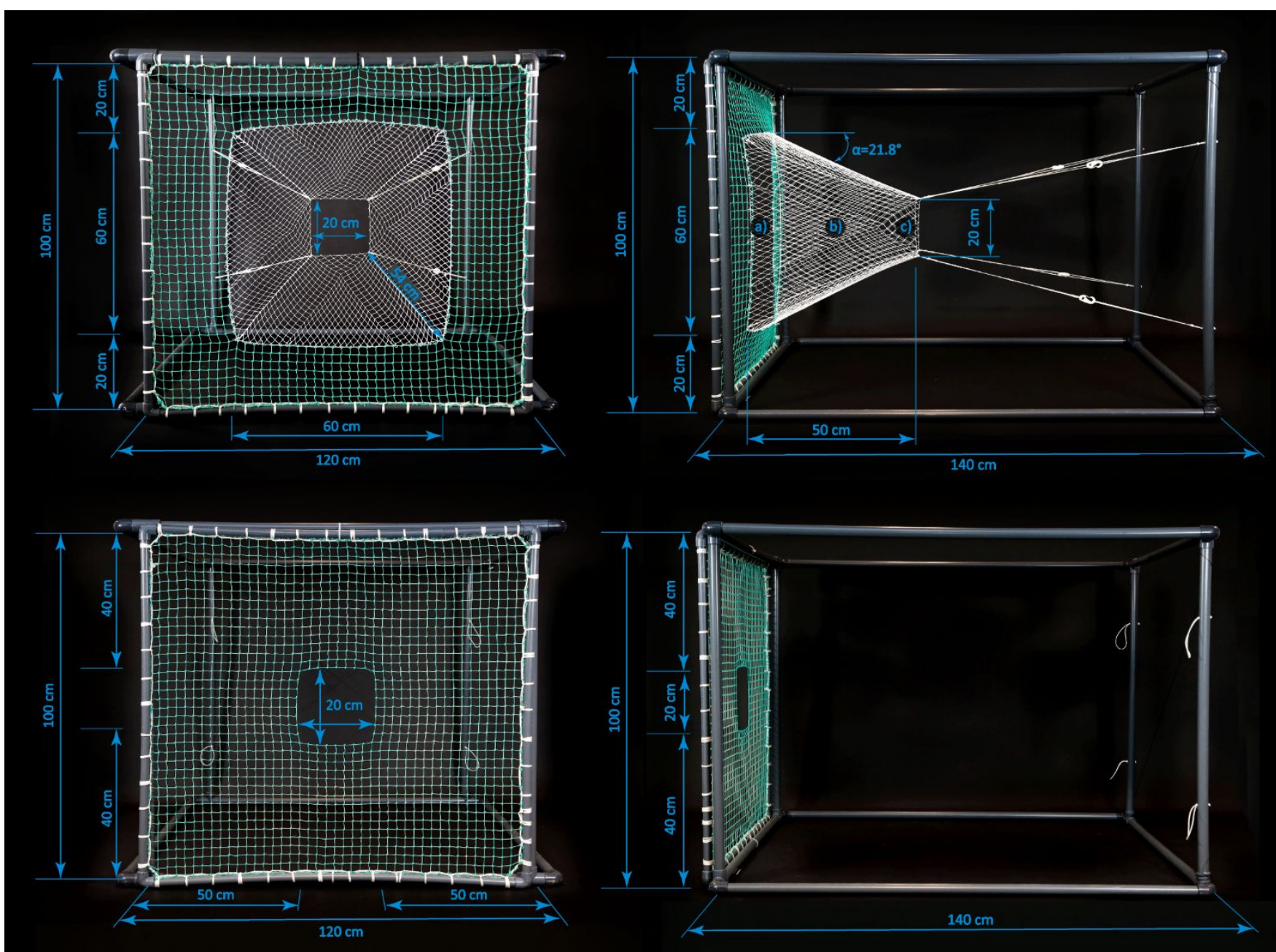

Figure 1. Above: 'Funnel' entrance (Fun hereafter; white PA funnel, $25 \mathrm{~mm}$ bar width, a $60 \times 60 \mathrm{~cm}$ outer opening and a $20 \times 20 \mathrm{~cm}$ inner opening, length $50 \mathrm{~cm}$ ) used for experiments. Left: front view; right: side view. The nomenclature describing the parts of a cod entrance is indicated on the upper side view: a) outer opening; b) funnel; c) inner opening. Below: The 'No funnel' entrance ('NoFun' hereafter). Left: front view; right: side view. Its single opening is also referred to as 'Inner opening' in the analysis.

Table 1. Description of pot entrances included in the experiments and to which triggers were attached. See Figure 1 for an illustration of entrance types.

\begin{tabular}{lllllll} 
Name & Abbreviation & $\begin{array}{l}\text { Twine type } \\
\text { PA = Polyamide } \\
\mathrm{d}=\text { diameter }\end{array}$ & $\begin{array}{l}\text { Mesh size } \\
\text { (bar width) } \\
{[\mathrm{mm}]}\end{array}$ & $\begin{array}{l}\text { Outer opening } \\
\text { dimension } \\
{[\mathrm{cm}]}\end{array}$ & $\begin{array}{l}\text { Funnel } \\
\text { length } \\
{[\mathrm{cm}]}\end{array}$ & $\begin{array}{l}\text { Inner opening } \\
\text { dimension } \\
{[\mathrm{cm}]}\end{array}$ \\
\hline 'Funnel' & Fun & $\begin{array}{l}\text { PA white } \\
\text { multifilament } \\
\mathrm{d}=0.9 \mathrm{~mm}\end{array}$ & 25 & $60 \times 60$ & 50 & $20 \times 20$ \\
\hline $\begin{array}{l}\text { 'No } \\
\text { funnel' }\end{array}$ & NoFun & - & - & & & \\
\hline
\end{tabular}

Movement was not limited inside the pot, and cod could move freely from one entrance to the other. To provide a long-lasting attractant to lure cod into the pot, we used a green fishing bait light typically used for pots and longlines (Bryhn et al., 2014). Data were collected in paired trials, each experimental trial consisting of two different entrances set together into the pot. To avoid possible bias resulting from cod side preferences, at least two replicates were conducted for each 
126 comparison, while switching the side of entrance types. Each individual trial was conducted from $127 \sim 14: 00 \mathrm{~h}$ to $13: 30 \mathrm{~h}$ the following day. For each trial, the cod were first set into the experimental pen 128 and then the pot was lowered into the net pen, starting the experiment.

\section{Fish-retention devices}

130 Parts for the NF triggers were sourced from the manufacturer Neptune marine products 131 (http://neptunemarineproducts.com/). The NF we tested was held together by two black '7-in end 132 pieces' on each side and a red 'regular finger unit' above and below. The regular finger units were 133 angled towards each other so that their fingertips were almost touching (Figure 2), according to the 134 manufacturer's instructions. The space between two fingers of the regular finger unit was $45 \mathrm{~mm}$. 135 The inner width of the NF frame was $19.5 \mathrm{~cm}$. 


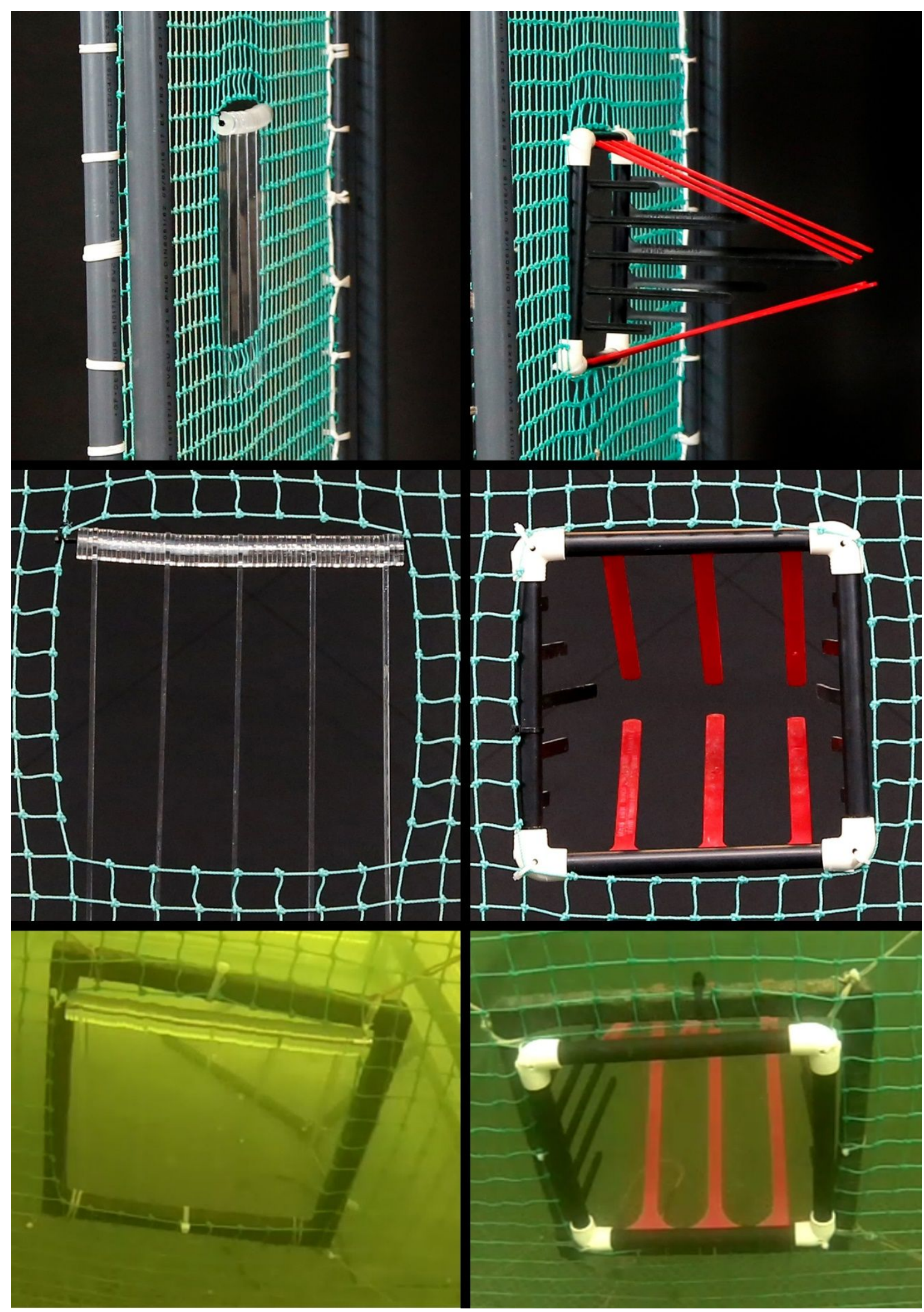

Figure 2. Acrylic fingers (AFs; left) and Neptune finger (NFs; right) attached to the NoFun entrance. First row side view in air, second row front view in air, last row front view underwater. For photos of triggers attached to the Fun entrance, see Figure appendix 5 .

The transparent triggers, named acrylic fingers (AF hereafter) were constructed from 3-mm thick acrylic glass, $266 \mathrm{~mm}$ long (Figure 3), laser cut to size. The fingers had pinholes in their head by 
153

which they were threaded onto a $2.5 \mathrm{~mm}$ aluminium rod. Fourteen round washers in the same material and thickness as the fingers' heads were spaced at $42 \mathrm{~mm}$ intervals on either sides of each finger. We chose a relatively large diameter for the head and washers to increase the fingers' side stability. We oriented the inter-finger space width to the $45 \mathrm{~mm}$ of the NF, setting it $3 \mathrm{~mm}$ smaller because the AFs are less rigid than the NFs. Furthermore, this is between the 40 and $45 \mathrm{~mm}$ pot selection windows mesh size that Ovegård et al. (2011) reported as having a $L_{50}$ of 32 and 38 cod total length and therefore was adequate to meet the $35 \mathrm{~cm}$ cod minimum conservation reference size (MCRS) for cod in the Baltic Sea. Assembled AF triggers had five fingers (Figure 2). Three additional washers were set at the outside of the two outer fingers. The AF's total width was $201 \mathrm{~mm}$. A cable tie on each end fixed washers and fingers in place while allowing them to turn up and down.

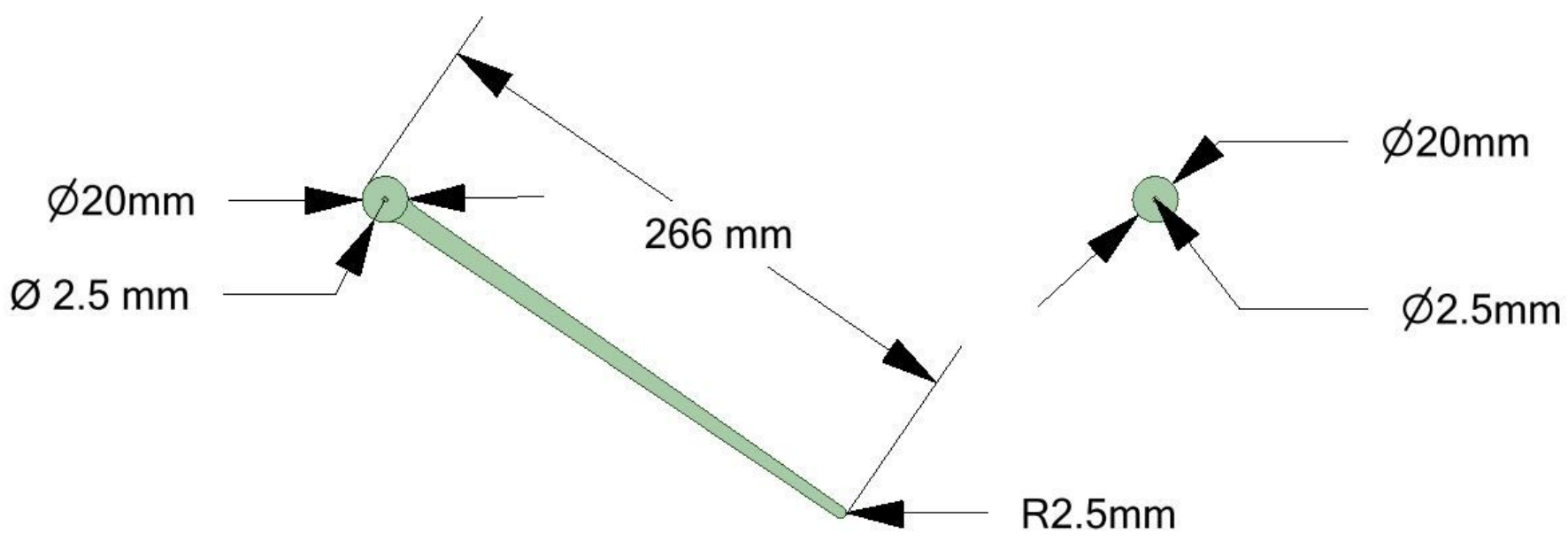

Figure 3. Dimensions of a finger of an AF trigger and an AF washer.

Both trigger types were attached to the entrances with thin white cable ties. The NoFun entrances equipped with the NF and AF triggers are hereafter referred to as NoFun+NF and NoFun+AF, respectively. The Fun entrances equipped with NF and AF triggers are hereafter referred to as Fun+NF and Fun+AF, respectively. The AFs were almost imperceptible underwater, whereas the NFs presented a distinct visual outline (Figure 2). The AFs were longer than the NoFun entrance height. Because the AF fingertips were hanging inside the pot, they could only be lifted towards the pot inside. In addition to its high transparency in water, the acrylic glass was chosen because its density is only slightly greater than water. Therefore, cod could easily lift the fingers when entering the pot.

\section{Fish observation}

Infrared (IR) camera system

To observe cod at night without influencing their behaviour, we developed an infrared (IR) lamp and camera system, known as infrared Fish Observation (iFO; Hermann et al., submitted). The system can record videos at visible and IR light and has a minimum observation range of $1.8 \mathrm{~m}$, sufficient video data storage capacities for several weeks, a rapidly swappable datadisk, and remote access connection through a webserver with live stream. In this study, we used two iFO systems, each with one camera and two IR lamps (Figures appendix 4 and 5; centroid frequency $850 \mathrm{~nm}$ ). IR light is often used to study fish in darkness, including cod (e.g. Meager et al., 2006; Utne-Palm et al., 2018). 
173 Radio-frequency identification (RFID) of cod

174 Cod were implanted with passive integrated transponders (PIT tags; $32 \mathrm{~mm}$ long half-duplex;

175 manufactured by Oregon RFID, Oregon, USA; permit 7221.3-1-009/18 of the Agency for agriculture,

176 food safety and fishery of the Federal State Mecklenburg-West Pomerania in Germany), and each

177 entrance was equipped with two radio-frequency identification (RFID) antennae (Figures appendix 3

178 and 4). However, owing to technical difficulties, we refrained from analysing these data.

179 Nevertheless, they were used to improve the manual analysis of the video recordings (see below) by

180 allowing us to pinpoint periods of increased entrance interaction before detailed video analysis and

181 by helping us to disaggregate event timings when several cod interacted simultaneously with an

182 entrance.

\section{Behavioural analysis}

184 To provide a comprehensive description of the event chain of cod interacting with the pot entrances, 185 we constructed a detailed ethogram and a behavioural flow diagram (Figure 4; Table 2), adapting 186 prior behavioural analysis approaches (Santos et al., submitted; Anders et al., 2016; Ljungberg et al., 187 2016; Meintzer et al., 2017). Most behavioural units were mutually exclusive events with quantifiable 188 duration. The exception was the brief $(<1 \mathrm{sec})$ touching of entrance structures, occurring when inside 189 the funnel or near the inner entrance opening (events 'net contact' or 'FRD contacts'). These contacts 190 could be directed inquisitive touches, usually during the day, or inadvertent bumping into the 191 entrance when trying to pass, most often at night. Cod leaving the camera field of view (FOV) for $<5$ 192 secs was considered staying within the same event. Videos were analysed with the software BORIS 193 (Behavioural Observation Research Interactive Software) version v. 7.9.7 (Friard and Gamba, 2016). 194 Each trial was fully analysed by one observer. 


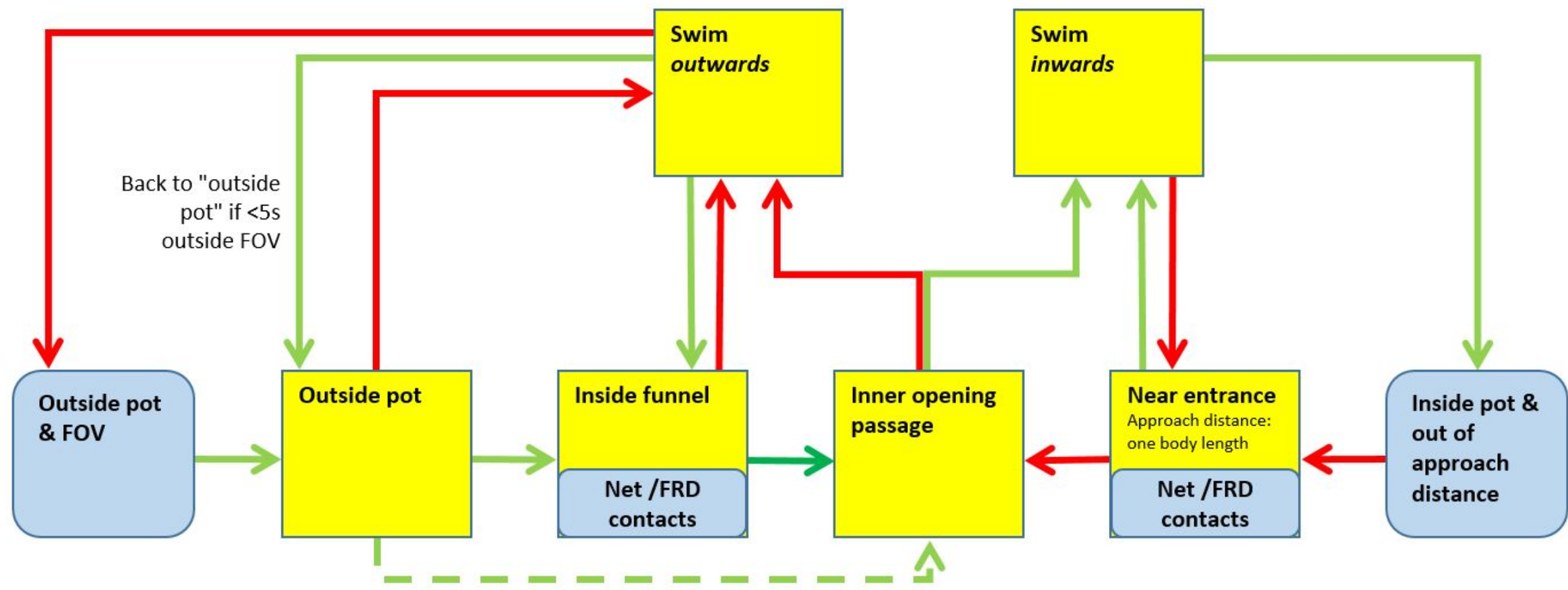

NoFun (+AF/+NF) - entrances

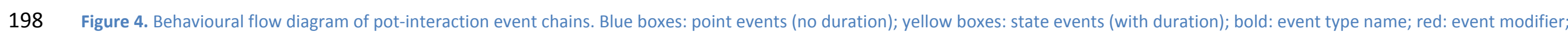

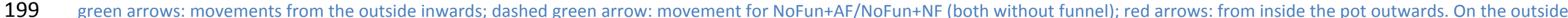

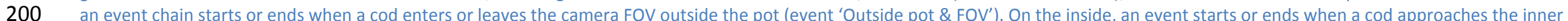
201 entrance opening to within one body length or increases its distance from it to more than one body length. 


\begin{tabular}{llll} 
Event & $\begin{array}{l}\text { Event } \\
\text { type }\end{array}$ & Description & Starting point \\
\hline $\begin{array}{l}\text { Outside } \\
\text { pot }\end{array}$ & State & $\begin{array}{l}\text { Cod is outside the pot entrance, gaze } \\
\text { directed Inwards: Cod enters FOV (begin event chain). }\end{array}$ & at entrance.
\end{tabular}

Outwards: When two-thirds of body length has passed outer entrance opening and cod does not directly leave FOV (previous event: 'Swim outwards').

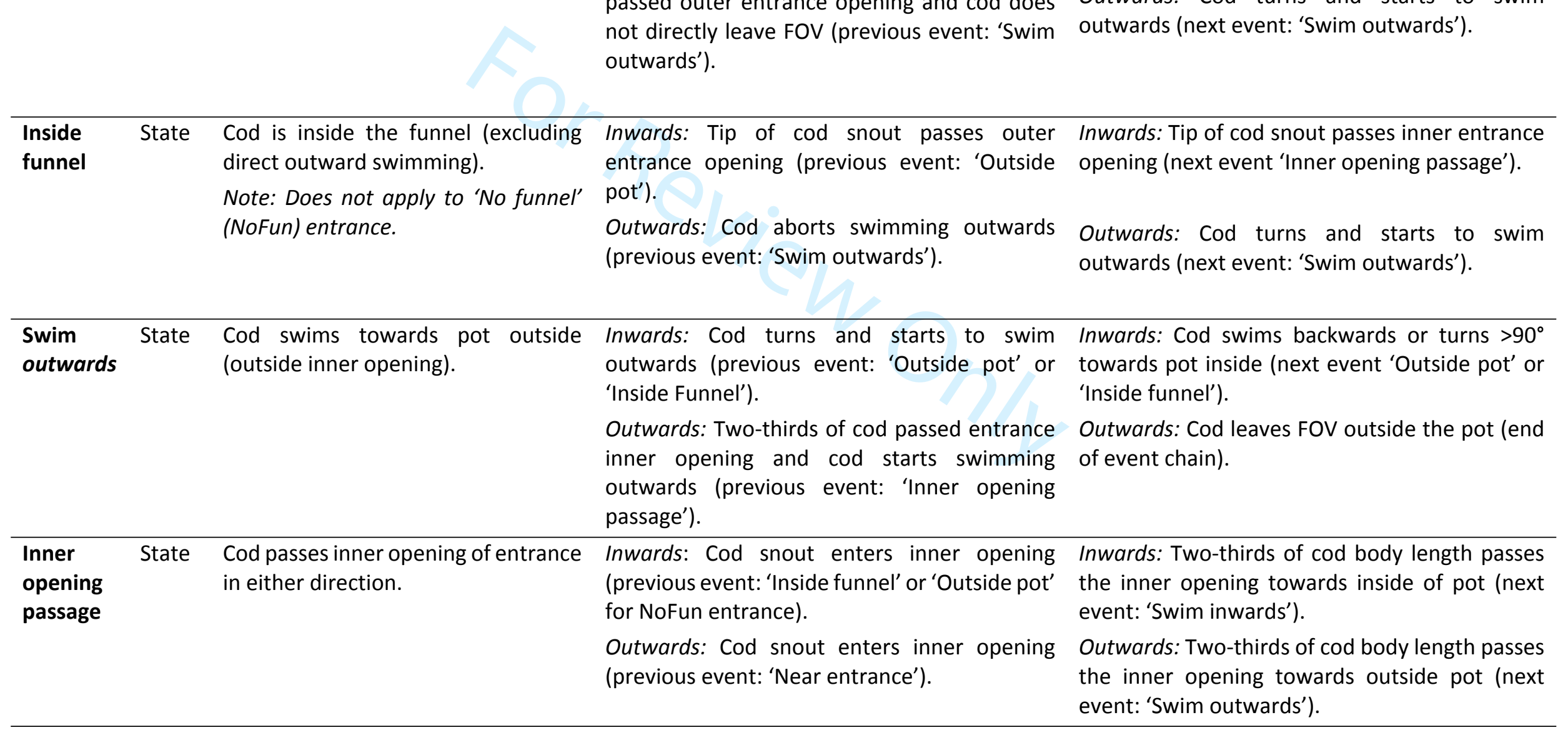

\section{Endpoint}

Inwards: Tip of cod snout passes outer entrance opening (next event: 'Inside funnel' or 'Inner opening passage' if 'No funnel' entrance).

Outwards: Cod turns and starts to swim outwards (next event: 'Swim outwards'). 


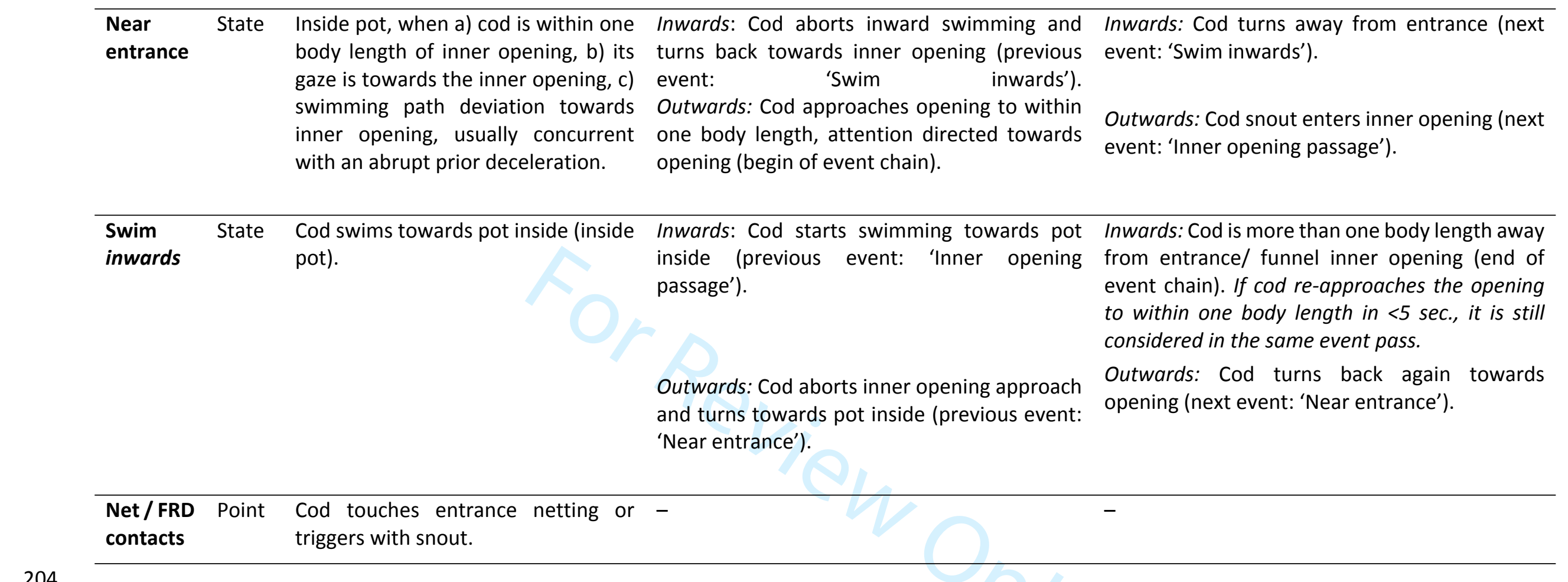




\section{Statistical analysis}

207

208

209

210

211

212

213

214

215

216

217

218

219

220

221

222

223

224

225

226

227

228

229

230

231

232

233

234

235

236

237

238

239

240

241

242

243

244

245

246

247

248

249

The pot-entrance catch-efficiency metric is a function of entry and exit/retention probability. 'Entry' is defined as the passage of a cod from outside the pot to inside the pot; 'exit' is defined as the passage of a cod from inside the pot to outside the pot. For each entry or exit event, a cod could choose either of the two entrances. Therefore, entries or exits observed in each experiment were treated as paired comparison data; for each experiment, one entrance was defined as 'control,' and the other was defined as 'test'. In experiments that compared the Fun entrance with the triggerequipped funnel, the Fun entrance was defined as control and the trigger entrances as test. In experiments that compared two trigger entrances, one of the AF entrances was defined as control and the other one as test. To address the research topics of the study, we used two different methods.

Using the first method, we compared the number of successful entries and exits of both entrance types, using a generalized linear model (GLM). A successful entry or exit is defined as a successful entrance passage by a cod starting outside the pot and ending inside the pot, or vice versa. An exploratory data analysis found no clear relationships between variables measured during the experiments and the probability of entry/exit in either test or control. Both entrance sides of the pot could be subjected to different physical conditions (e.g. currents or illumination) that might influence the entrance choice of a cod trying to enter or exit the pot, therefore confounding the effect of the entrance design itself. To balance this potential side effect, 'side' was included in the model as a blocking factor. Initially, we also considered including 'day period' in the full model with the two states: 'day' (the time between sunrise and sunset) and 'night' to reflect possible differences in diurnal entrance/exit patterns. Day period information (sunset, sunrise, civil dawn, civil dusk) were acquired using $R$ suncalc package (Thieurmel and Elmarhraoui, 2019). Time is in local time (CET = UTC+1h). Because there were almost no entries or exits at night, however, we only included side as a covariate. For each pairwise comparison, the entry and exit proportion was modelled as follows:

Being $\mathrm{I} / \mathrm{O}$, the binary variable expressing the entrance used by the observed fish to enter (I) or exit $(0)$ the pot $(0=$ control, $1=$ test $)$, and $X$ a three-dimensional vector including the model intersect, and the dummy variable representing side where the test is positioned ( $0=$ left, $1=$ right), then $p(X)=p(\gamma=1 \vee X)$ is the expected probability of either entry or exit through the test, conditioned to side. A $p(X)$ of 0.5 indicates no difference between test and control entrance; values less than 0.5 indicate lower entry or exit rates for the test entrance than for the control entrance. The binary GLM applied expresses $p(X)$ as:

$$
\log \left(p(X) /(1-p(X))=\beta_{0}+\beta_{1} *\right. \text { side }
$$

On the right model side, the coefficient $\beta_{0}$ is the model intercept, and $\beta_{1}$ quantifies the potential effect of side on entry and exit probability through the test entrance. The models were fitted with the statistical software R (3.6.3, R Core Team, 2020). In addition to Model (1), the second model, without side was calculated and the final model selected from the two candidates using AIC (Akaike, 1973). If the side effect was kept in the model, its effect was assessed using the sum-to-zero contrast available for GLM models in the statistical analysis program R. In general, pot efficiency, and more particularly pot-entrance efficiency, depends on the ratio between fish entry and exit rates (Furevik, 1994; Hedgärde et al., 2016). Therefore, the product of $p(I)$ and $p(O)$ can be interpreted as a metric of catch efficiency of the test entrance relative to the control entrance. Assuming that the relative probabilities of entry or exit through the test or control are the same $(p(I)=0.5$ and $p(O)=$ $0.5)$, then the relative catch efficiency calculated for the test entrance should not be significantly 
250 different from 0.25 . Because the calculations involve two antagonist selective processes, 251 improvements in relative catch efficiency need to be interpreted by considering the trade-offs 252 between $p(I)$ and $p(O)$. To allow for indirect catch-efficiency comparisons between the trigger 253 types, the GLM-calculated entry and exit probabilities of the comparisons between the trigger and 254 255 256 257 258 259 the Fun entrance were plotted against each other.

The GLM analysis is a coarse first approach to quantifying entry and exit probabilities of the test entrance relative to the control entrance. However, this does not reveal the underlying mechanism leading to possible differences in interaction and does not allow the incorporation of the information provided by aborted entry or exit attempts. Therefore, using the second statistical method, we investigated at which point in the event chain do control and test entrance types provoke different reactions from the interacting cod. We adapted and applied the hierarchical tree classification method of Santos et al. (submitted). The individual event chains of cod-entrance interactions are pooled for each experiment and across replicates. These event chains are then arranged in an inverted tree-like structure with the root containing the total number of observations on top. The behavioural nodes in the level immediately below the root each contain the number of observed entry/exit events, either in the test or the control entrance. After this first level, different event chains were encompassed in one branch up to the parent node where they differed. At this point, the event chains split into branches, when each one could once again contain several event chains that separated at lower event levels, creating the tree. The terminal leaves at the end of each event chain represented the final fate of the observed cod 'Inside pot' or 'Outside pot'. Based on the information contained in the tree, the marginal probability (MP) for a given behavioural event to happen is calculated as:

$$
M P=P\left(N_{i}\right)=\frac{N_{i}}{R o o t}
$$

272

273

274

275

276

277

278

279

280

281

282

283

284

285

286

Where $N_{i}$ is the number of cod performing the event $i$ (node $i$ ) and Root is the total number of observed interactions. Similarly, the conditional probability (CP) that an event $i$ could happen, given that the parent node $k$ in the level immediately above happened, is:

$$
C P=P\left(N_{i} \vee N_{k}\right)=\frac{N_{i}}{N_{k}}
$$

Trees were constructed for each experiment, once for entrance interactions starting outside the pot and once starting inside the pot. To account for behavioural variability that occurs naturally between and within experimental replicates, we adapted and applied a double bootstrap method often used in trawl selectivity studies (Millar, 1993; Millar, 1993). Each iteration of the bootstrap produces an artificial tree after resampling experimental replicates and observations within the resampled replicates. This procedure was repeated $B=1000$ times, leading to 1000 artificial trees, allowing calculation of $95 \%$ Efron-percentile Confidence Intervals associated with the average probabilities (Equations 2 and 3) from the empirical tree (Santos et al., submitted, 2016). The resulting trees were inspected for differences in event-chain flows and event links of both main entrance branches, based on MP and CP. Little or no Cl overlap between the same event-chain links of both entrance types was interpreted as significant differences. 


\title{
Results
}

In total, we analysed 18 trials with a total duration of $407.19 \mathrm{~h}$ (Table appendix 1 ). Sometimes, the video cameras failed and stopped recording for short periods (seconds to minutes). To avoid bias caused by camera failure on one of the two entrances, those periods were excluded from analysis of both entrances. Most entrance passages occurred during day (204 of all 221 observed entries and 90 of all observed 96 exits). In the first two experiments, we compared triggered entrances with the Fun entrance, representative of a basic funnelled entrance without triggers. In the last three experiments, we compared the AF and NF triggers directly (Table 3).

\begin{abstract}
Table 3. Overview of the number of entries and exits for all trials conducted for different entrance type combinations. By definition, the Fun entrance without triggers was the control entrance when one of the two tested entrances was equipped with a trigger. In trials comparing Fun entrances with triggered entrances, the Fun entrance was defined as control. In trials where both entrances were equipped with triggers, an entrance equipped with the AF triggers was defined as 'Control'. 'Position control' describes the pot side on which the control entrance was situated. The number of entries and exits trough test/control entrances is given.
\end{abstract}

Entries

Exits

\begin{tabular}{|c|c|c|c|c|c|c|c|c|}
\hline Exp. & Control & Test & $\begin{array}{l}\text { Position } \\
\text { control }\end{array}$ & $\begin{array}{l}\text { Cod } \\
\text { length } \\
\text { group } \\
{[\mathrm{cm}]}\end{array}$ & Control & Test & Control Test & \\
\hline \multirow[t]{6}{*}{1} & Fun & Fun $+A F$ & left & $40-49$ & 2 & 6 & 0 & 0 \\
\hline & Fun & Fun $+A F$ & left & $50-59$ & 14 & 5 & 10 & 0 \\
\hline & Fun & Fun $+A F$ & left & $50-59$ & 8 & 6 & 8 & 0 \\
\hline & Fun & Fun $+A F$ & right & $40-49$ & 7 & 9 & 9 & 0 \\
\hline & Fun & Fun $+A F$ & right & $30-39$ & 5 & 3 & 1 & 0 \\
\hline & & & & 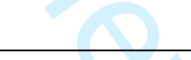 & 36 & 29 & 28 & 0 \\
\hline \multirow[t]{6}{*}{2} & Fun & Fun+NF & right & $40-49$ & 9 & 0 & 2 & 0 \\
\hline & Fun & Fun+NF & left & $40-49$ & 13 & 1 & 6 & 0 \\
\hline & Fun & Fun+NF & left & $40-49$ & 5 & 3 & 0 & 0 \\
\hline & Fun & Fun+NF & right & $30-39$ & 6 & 2 & 2 & 0 \\
\hline & Fun & Fun+NF & right & $40-49$ & 6 & 4 & 3 & 0 \\
\hline & & & & & 39 & 10 & 13 & 0 \\
\hline \multirow[t]{4}{*}{3} & Fun $+A F$ & NoFun+AF & left & $30-39$ & 18 & 4 & 0 & 13 \\
\hline & Fun $+A F$ & NoFun+AF & right & $30-39$ & 11 & 0 & 1 & 2 \\
\hline & Fun $+A F$ & NoFun+AF & left & $40-49$ & 20 & 16 & 1 & 31 \\
\hline & & & & & 49 & 20 & 2 & 46 \\
\hline \multirow[t]{3}{*}{4} & Fun $+A F$ & Fun+NF & right & $30-39$ & 7 & 1 & 0 & 0 \\
\hline & Fun $+A F$ & Fun+NF & left & 30-39 & 4 & 1 & 0 & 0 \\
\hline & & & & & 11 & 2 & 0 & 0 \\
\hline \multirow[t]{4}{*}{5} & NoFun+AF & NoFun+NF & left & $30-39$ & 7 & 1 & 0 & 0 \\
\hline & NoFun+AF & NoFun+NF & right & $30-39$ & 6 & 1 & 5 & 0 \\
\hline & NoFun+AF & NoFun+NF & right & 30-39 & 9 & 1 & 2 & 0 \\
\hline & & & & & 22 & 3 & 7 & 0 \\
\hline
\end{tabular}


Table 4. GLM parameters of all final experiment models. Exp. = experiment number, second and third columns on the left = entrances in experiment; 'Model' $=$ entry or exit model; 'side' =

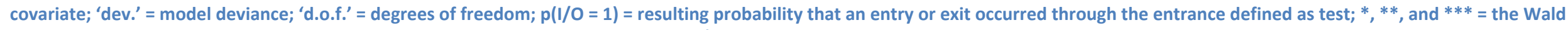
test $p$-value is $<0.05,<0.01$, and $<0.001$, respectively. Significant values are in bold. $\mathrm{N} / \mathrm{I}=$ 'Not included' in the final model. Please note that, for the experiment Fun+AF vs. NoFun+AF, the selected model included the 'side' covariate owing to a perfect separation by the side covariate. Therefore, the model without the side covariate added is in italics.

\begin{tabular}{|c|c|c|c|c|c|c|c|c|c|c|c|c|}
\hline Exp. & $\begin{array}{l}\text { Entrance } \\
\text { Control }\end{array}$ & $\begin{array}{l}\text { Entrance } \\
\text { Test }\end{array}$ & Replicates & Model & $n$ Control & $n$ Test & Intercept & side & dev. & d.o.f. & $p(1 / 0=1)$ & Notes \\
\hline \multirow[t]{2}{*}{1} & Fun & Fun+AF & 5 & Entries & 36 & 29 & -0.216 & $N / I$ & 89.35 & 64 & $\begin{array}{l}0.45(0.33- \\
0.57)\end{array}$ & \\
\hline & & & & Exits & 28 & 0 & No exits through triggers & & & & 0 & \\
\hline \multirow[t]{2}{*}{2} & Fun & Fun+NF & 5 & Entries & 39 & 10 & $-1.361 * * *$ & $\mathrm{~N} / \mathrm{I}$ & 49.59 & 48 & $\begin{array}{l}0.20(0.11- \\
0.34)\end{array}$ & \\
\hline & & & & Exits & 13 & 0 & No exits through triggers & & & & 0 & \\
\hline \multirow[t]{3}{*}{3} & Fun+AF & NoFun+AF & 3 & Entries & 49 & 20 & -9.604 & 8.96 & 74.73 & 67 & $\begin{array}{l}0.0001(0- \\
\mathrm{NaN})\end{array}$ & $\begin{array}{l}\text { Entries } \\
\text { model }\end{array}$ \\
\hline & & & & Entries & 49 & 20 & $-0.896 * * *$ & $N / I$ & 83.079 & 68 & $\begin{array}{l}0.29(0.20- \\
0.41)\end{array}$ & $\begin{array}{l}\text { without } \\
\text { 'side' } \\
\text { added }\end{array}$ \\
\hline & & & & Exits & 2 & 46 & $2.239 * *$ & 1.55 & 13.41 & 46 & $\begin{array}{l}0.90(0.66- \\
0.99)\end{array}$ & \\
\hline \multirow[t]{2}{*}{4} & Fun+AF & Fun+NF & 2 & Entries & 11 & 2 & $-1.705^{*}$ & $N / I$ & 11.16 & 12 & $\begin{array}{l}0.15(0.04- \\
0.45)\end{array}$ & \\
\hline & & & & Exits & 0 & 0 & $\begin{array}{l}\text { No exits through either } \\
\text { triggers }\end{array}$ & & & & - & \\
\hline \multirow[t]{2}{*}{5} & NoFun+AF & NoFun+NF & 3 & Entries & 22 & 3 & $-1.992^{* *}$ & $N / I$ & 18.35 & 24 & $\begin{array}{l}0.12(0.04- \\
0.31)\end{array}$ & \\
\hline & & & & Exits & 7 & 0 & Only 7 exits through $\mathrm{AF}$ & & & & 0 & \\
\hline
\end{tabular}




\section{Comparison triggers with funnel entrance}

308 Funnel entrance vs. Funnel+acrylic fingers entrance

309 Five replicates were conducted of the experiment comparing the Fun entrance (control) with the 310 Fun+AF entrance (test; Table 3). The final model for the entries included only the non-significant 311 intercept, indicating that there was no side effect on entry probabilities (Table 4). Entry rate $p(I=1)$ 312 of the Fun+AF entrance was $0.45(0.33-0.57)$, similar to the Fun entrance (0.5). Although there were 313 more approaches to the Fun entrance, Cls overlap, and the proportions of cod entering either funnel 314 were almost identical, as were the final proportions of cod passing the entrance to the pot inside. 315 This revealed that cod moved through both entrances equally, explaining the absence of a trigger 316 effect on entrance probabilities (Figure 5).

All 28 observed exits were through the Fun entrance and significantly more cod approached 318 the Fun from inside, revealing an AF exit-impeding effect (Figure 6). 

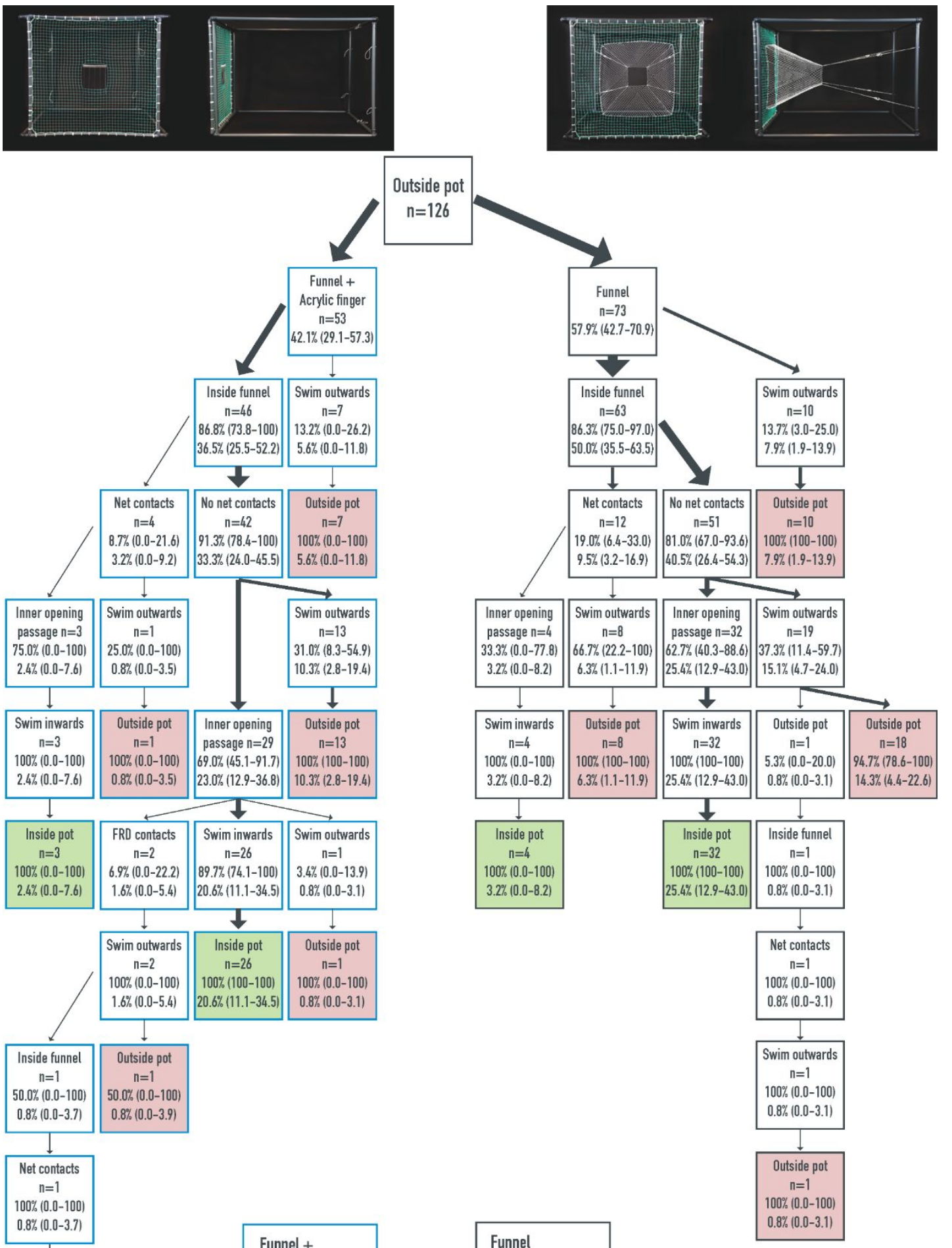

\begin{tabular}{|c|}
\hline Net contacts \\
$n=1$ \\
$100 \%(0.0-100)$ \\
$0.8 \%(0.0-3.7)$
\end{tabular}

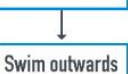

$n=1$

$\mathrm{n}=1$
$100 \%(0.0-100)$

$0.8 \%(0.0-3.7)$

Outside pot

$n=1$

$100 \%(0.0-100)$

Figure 5. Behavioural event-chain tree comparing the Fun entrance (control) with the Fun+AF entrance (test) for interactions of cod with pot entrances starting outside. Each box represents an event type; the first line = event type name; the second line = number of times this event was observed at this point in the event chain; the third line = the marginal probabilities (MP) related to the total number of interactions; the last line = the conditional probabilities (CP) 
related to the number of interactions in the parent link (the link above a respective link). Confidence intervals are based on 1000 bootstrap iterations.
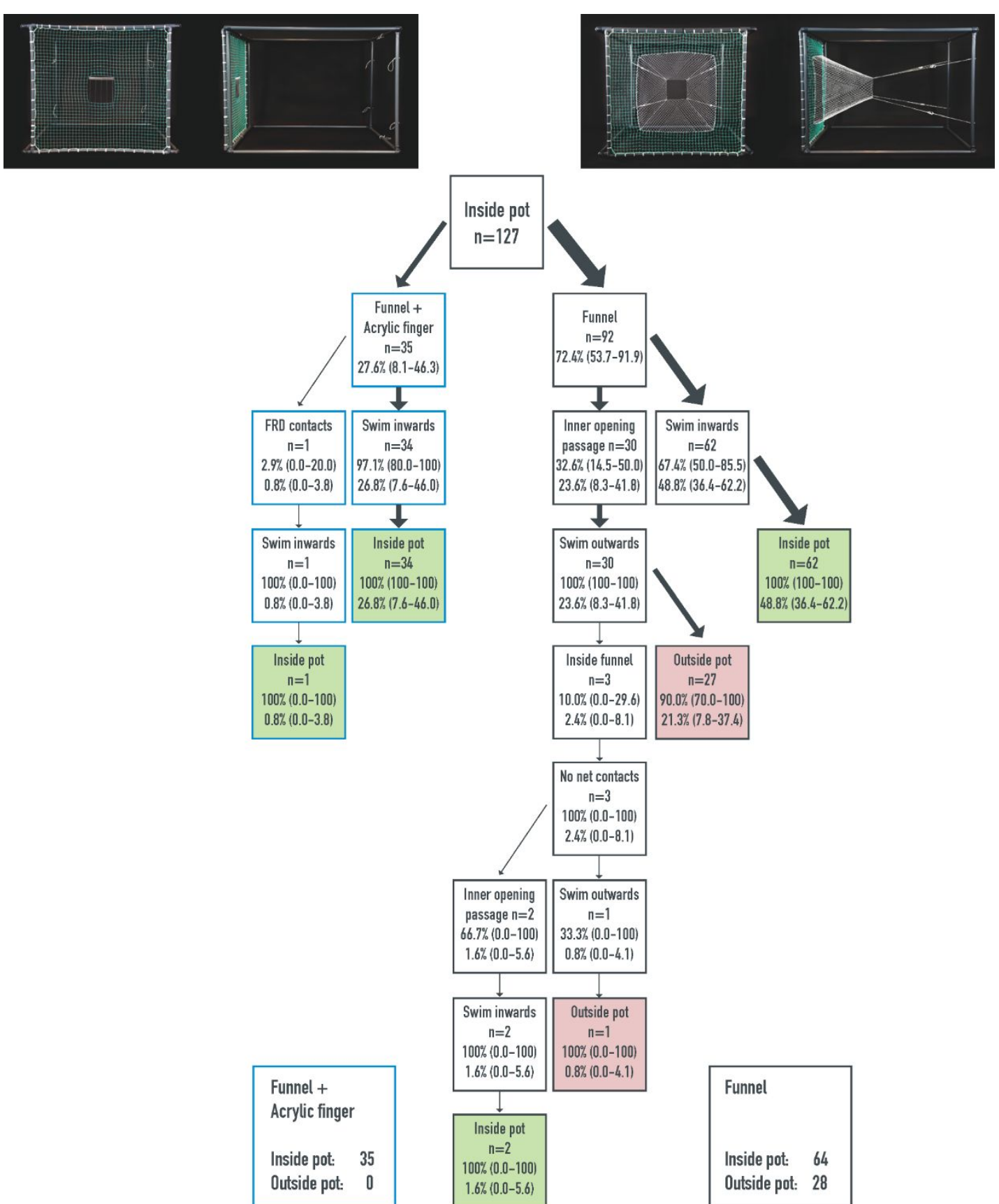

Funnel

Inside pot: 64

Outside pot: 28

Figure 6. Behavioural event-chain tree comparing the Fun entrance (control) with the Fun+AF entrance (test) for interactions of cod with pot entrances starting inside. Each box represents an event type; the first line = event type name; the second line = number of times this event was observed at this point in the event chain; the third line = the marginal probabilities (MP) related to the total number of interactions; the last line $=$ the conditional probabilities (CP) related to the number of interactions in the parent link (the link above a respective link). Confidence intervals are based on 1000 bootstrap iterations.

Funnel entrance vs. Funnel+Neptune fingers entrance

Five replicates were conducted of the experiment comparing the Fun entrance with the Fun+NF entrance (Table 3 ). The final model for the entries included only the highly significant negative intercept, $p(I=1)$, which was 0.20 (0.11-0.34; Table 4). No significant differences between the proportions of cod approaching and entering either funnel were observed (Figure 7). There was a 
339 difference in the number of entries because significantly more of the cod that entered the Fun 340 entrance passed the inner opening towards the pot inside than those that entered the trigger341 equipped funnel. This only applies to interactions without net contacts; there were too few 342 interactions with net contacts to allow for conclusions.

343 Significantly more of inside entrance approaches were to the Fun entrance (Figure 8). All 13 344 exits were through the Fun entrance and all approaches to the triggers were aborted exit attempts. 345 One cod managed to pass from inside the pot through the NF into the funnel, but then turned 346 around again and passed them a second time back towards the pot inside. This occurred at night. It 347 appears that the cod was not able to orient itself in the dark and passed through the NF by chance 348 after hitting it from above while swimming. After passing the triggers, it bounced chaotically into the 349 funnel netting, appearing as if it was trying to push through it and finally was deflected back towards 350 the NF, then passing it back into the pot. These results reveal a strong exit- as well as an entry351 impeding effect of the NF. 


\section{1}

2

5

6
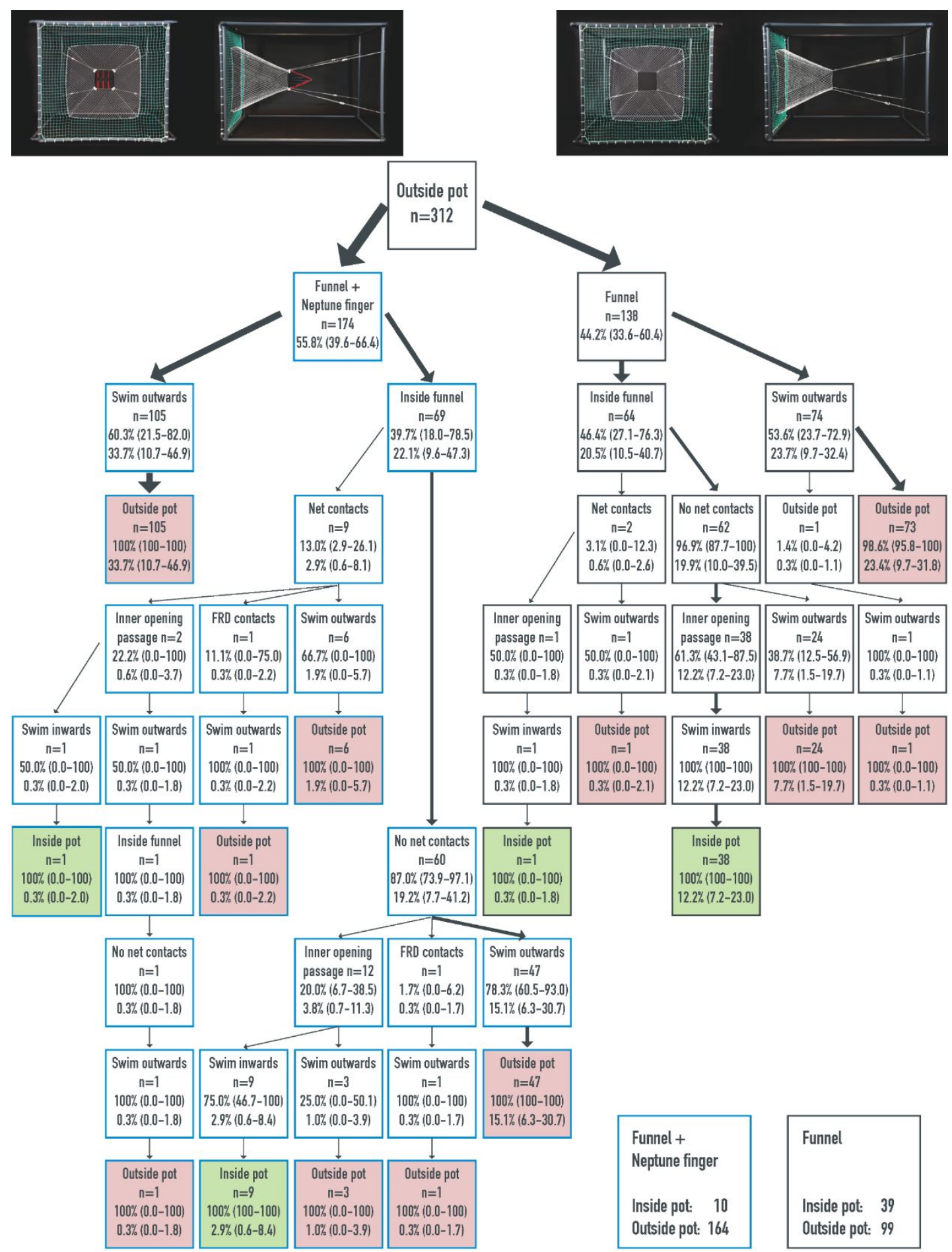

Figure 7. Behavioural event-chain tree comparing the Fun entrance (control) with the Fun+NF entrance (test) for interactions of cod with pot entrances starting outside. Each box represents an event type; the first line = event type name; the second line = number of times this event was observed at this point in the event chain; the third line = the marginal probabilities (MP) related to the total number of interactions; the last line $=$ the conditional probabilities (CP) related to the number of interactions in the parent link (the link above a respective link). Confidence intervals are based on 1000 bootstrap iterations. 

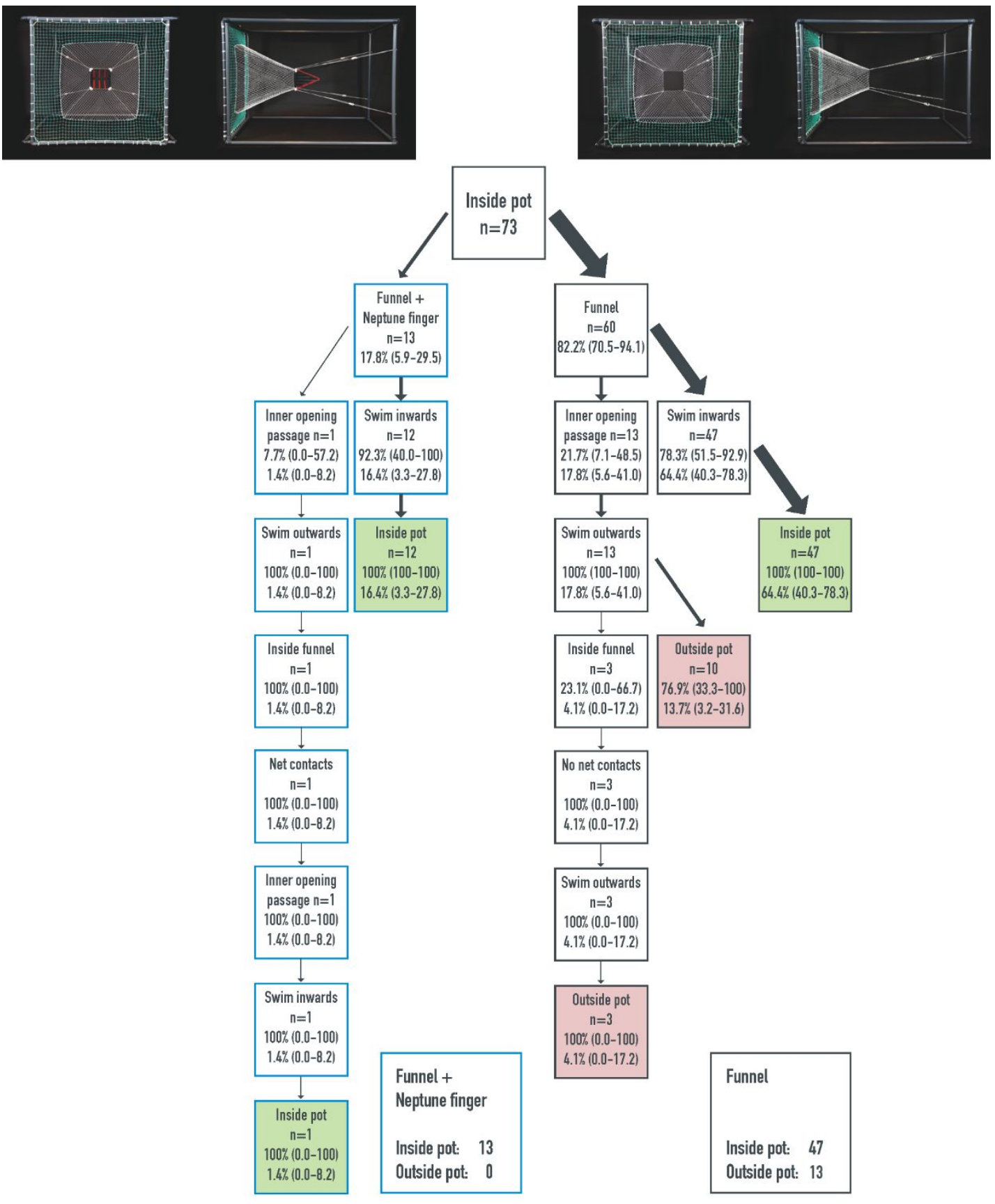

360 Figure 8. Behavioural event chain tree comparing the Fun entrance (control) with the Fun+NF entrance (test) for 361 interactions of cod with pot entrances starting inside. Each box represents an event type; the first line = event type name; the second line $=$ number of times this event was observed at this point in the event chain; the third line = the marginal probabilities (MP) related to the total number of interactions; the last line = the conditional probabilities (CP) related to the number of interactions in the parent link (the link above a respective link). Confidence intervals are based on 1000 bootstrap iterations. 
Comparison of catch efficiencies

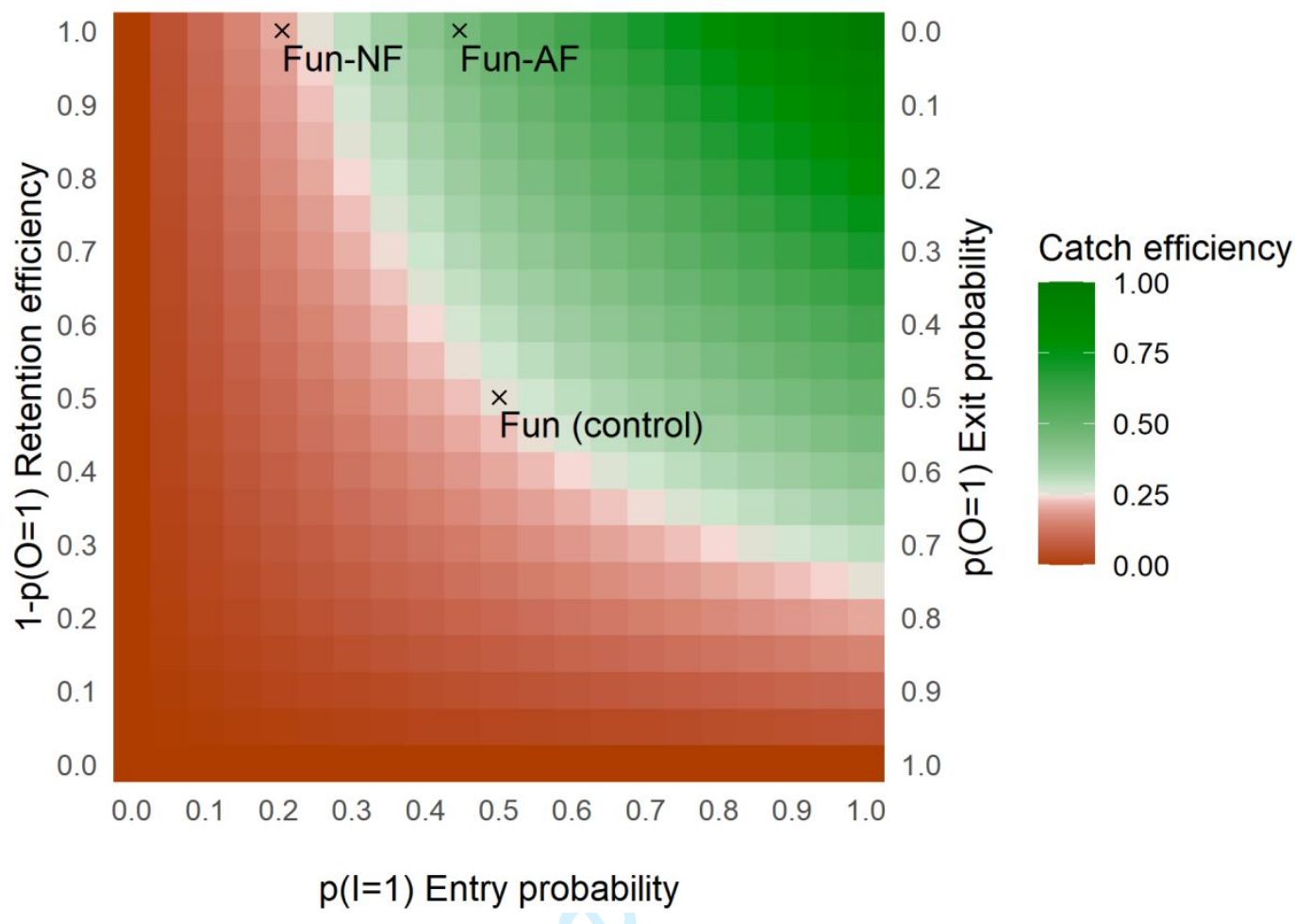

Figure 9. Catch-efficiency comparison from experiments comparing the Fun entrance (control) with the Fun+AF and Fun+NF entrances (test).

Although no exits occurred through both trigger types, only the Fun+AF entrance (catch efficiency = 0.446) performed better than the Fun control entrance, because almost no cod entered the pot through the NF (Figure 9; catch efficiency Fun+NF $=0.204$ ). Both trigger types were rarely touched in attempted entries and exits, indicating that triggers are inspected primarily visually and that the NF deterring effect is visual.

\section{Direct trigger entrance comparisons}

376 Funnel+acrylic fingers vs. Funnel+Neptune fingers entrance

377 The Fun+AF and the Fun+NF were compared in two replicates. The Fun+AF entrance was set as control $378(p(I / O=0))$ for the GLM. The entries' final model included only the significant negative intercept; the 379 probability for entry through Fun+NF entrance $(p(I=1))$ was $0.15(0.04-0.45)$, revealing a clear 380 preference of the cod to enter the pot through the AF-equipped entrance. The behavioural event tree, 381 however, did not mirror this result; there was no significant difference in the number of cod 382 approaching or passing either entrance (Figure 10). This, however, could be the result of the low 383 sample size of only 13 pot entries in total. This small number of entries resulted from both trigger types 384 blocking the cod from exiting. In the second trial of this experiment, the last of all trials conducted in 385 the study, only five of the seven cod in the experiment entered the pot.

Both trigger-equipped openings were approached from the inside nine times (Figure 11), only permitting the statement that both triggers were strongly deterring for cod inside the pot. This number of inside interactions is markedly smaller than in the experiments comparing one trigger type with the Fun entrance without trigger. It indicates that the passage of a trigger-equipped entrance, 390 necessitating physical contact with the trigger, is a deterring process, inhibiting subsequent reapproaches to the trigger-equipped entrances. Notwithstanding the small approach numbers, 
significantly fewer cod approached the Fun+NF from inside, also reflecting the deterrent effect of the 393 NF observed in the prior experiments.
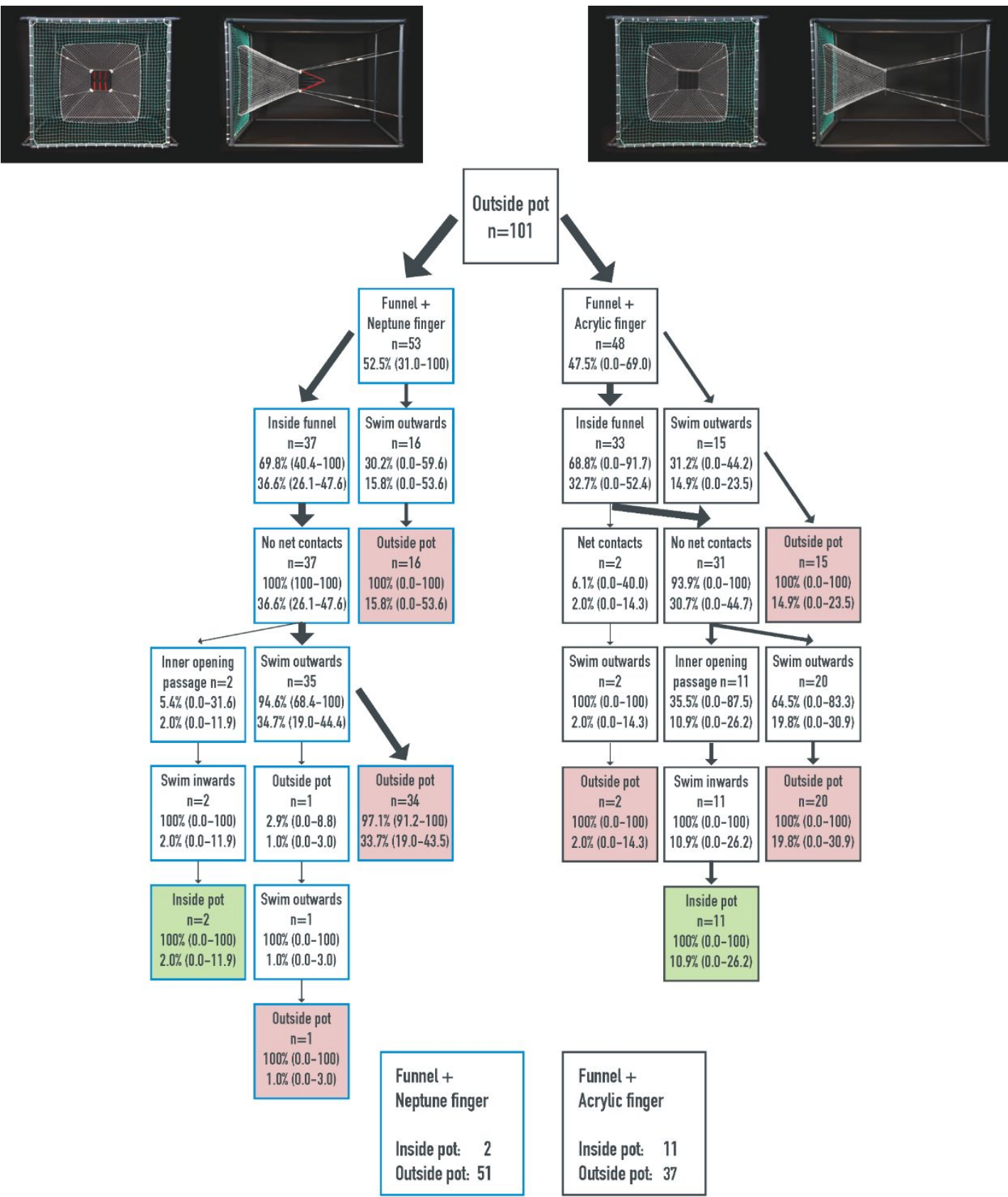

Figure 10. Behavioural event-chain tree comparing the Fun+AF entrance (control) with the Fun+NF entrance (test) for interactions of cod with pot entrances starting outside. Each box represents an event type; the first line = event type name; the second line $=$ number of times this event was observed at this point in the event chain; the third line = the marginal probabilities (MP) related to the total number of interactions; the last line = the conditional probabilities (CP) related to the number of interactions in the parent link (the link above a respective link). Confidence intervals are based on 1000 
402

403

404

405

406

407

408

409

410

411

412

413

414

415

416

417

418

419

420
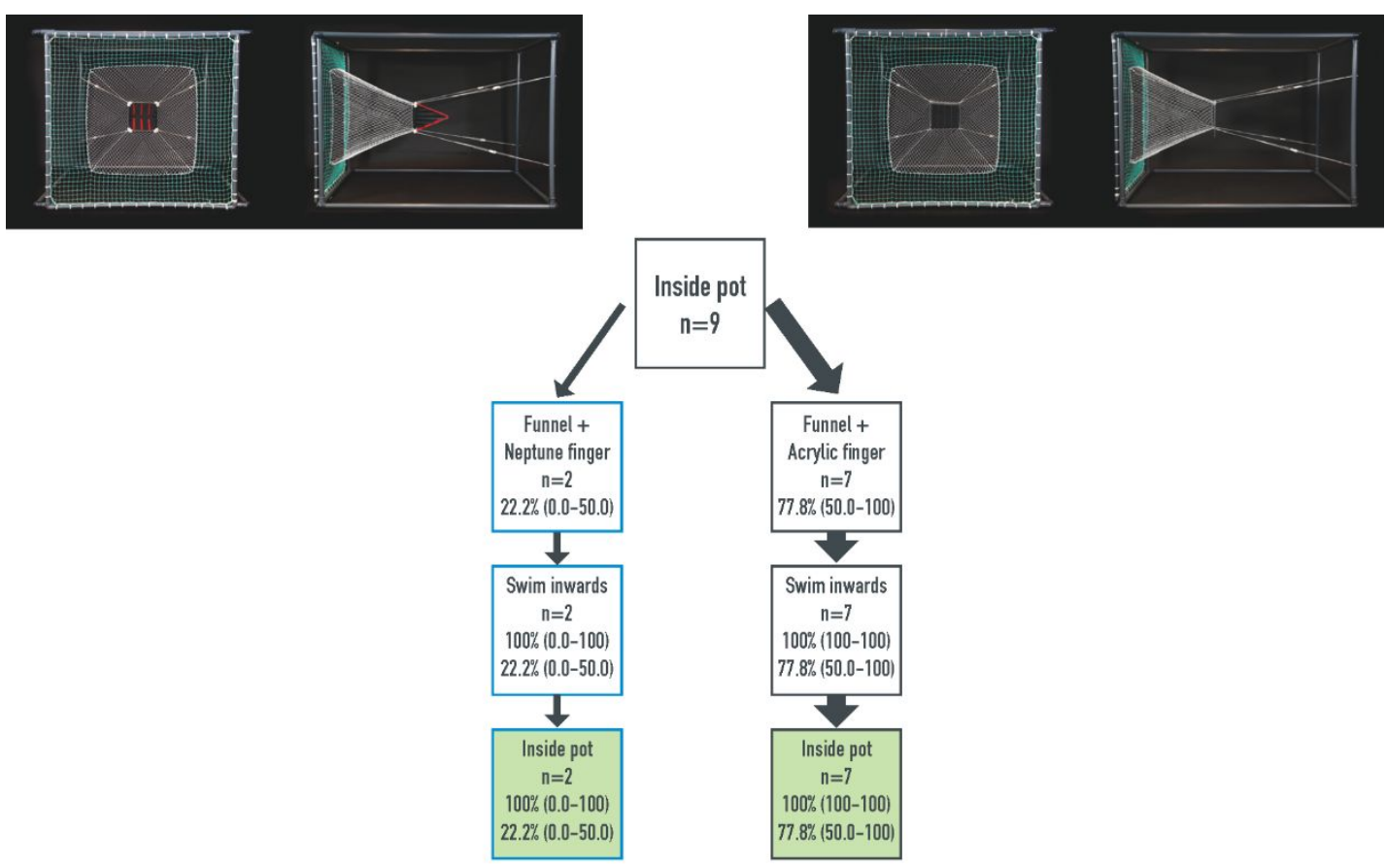

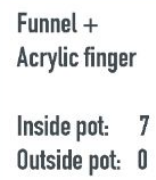

Figure 11. Behavioural event-chain tree comparing the Fun+AF entrance (control) with the Fun+NF entrance (test) for interactions of cod with pot entrances starting outside. Each box represents an event type; the first line = event type name; the second line $=$ number of times this event was observed at this point in the event chain; the third line $=$ the marginal probabilities (MP) related to the total number of interactions; the last line = the conditional probabilities (CP) related to the number of interactions in the parent link (the link above a respective link). Confidence intervals are based on 1000 bootstrap iterations.

\section{Funnel+acrylic fingers vs. No Funnel+acrylic fingers entrance}

We compared the Fun+AF and the NoFun+AF entrances in three replicates, with the Fun+AF entrance set as control $(p(I / O=0))$ for GLM. The final model included the intercept and the side covariate; as in one of the trials, no cod entered through the NoFun+AF entrance. Therefore, we classified this as a perfect separation (Allison, 2008) by the side covariate and proceeded to describe the calculated entry probabilities with the model excluding the side covariate, although its AIC was higher. We consider this a not ideal, albeit adequate, procedure to calculate the resulting test entry probability, considering that, in all other experiments, the side covariate was not included in the AIC-selected models, indicating that there was no side effect. This model returned a significantly lower entry probability through the NoFun+AF $(0.29(0.20-0.41))$. The behavioural event-chain tree of outside interactions (Figure 12) reveals that the higher entry rate of Fun+AF entrance resulted from significantly more interactions with it. For both entrances, the number of cod that had approached the NoFun+AF entrance and then passed it towards inside (Event type 'Inside opening passage') is similar.

Cod exited almost exclusively through the NoFun+AF entrance. The final exit model included only the significant intercept; the probability that an exit occurred through the NoFun+AF entrance ( $p(O=1))$ was $0.90(0.66-0.99)$. This was caused by significantly more of the entrance interactions from the inside occurring with the NoFun+AF entrance (Figure 13). The result of this experiment, where both entrances were equipped with the same triggers, demonstrates that combining triggers with a funnel considerably increases catch efficiency by increasing entrance contact probability of 
428 cod approaching the pot from outside (= increase in entry probability) and decreasing contact

429 probability for cod inside the pot (= decrease in exit probability). This also fits with the low number of 430 inside interactions with either triggered funnel in the Fun+AF vs. Fun+NF experiment.

In contrast to the other experiments including the AF, cod were able to pass them towards the outside. In the first two trials, the length distribution of the cod was 320-390 mm and 300-360 $\mathrm{mm}$, respectively. Those cod were small enough to pass between two fingers without touching them. The cod in the third trial, however, were between $400-430 \mathrm{~mm}$; those cod were not able to pass between the fingers without touching them. Here, we observed that they were able push through two adjacent AF fingers. This demonstrates that the distance between two fingers was too large and/or the fingers were not rigid enough or not assembled tightly enough to resist sideways bending or displacement by cod pushing against them. 

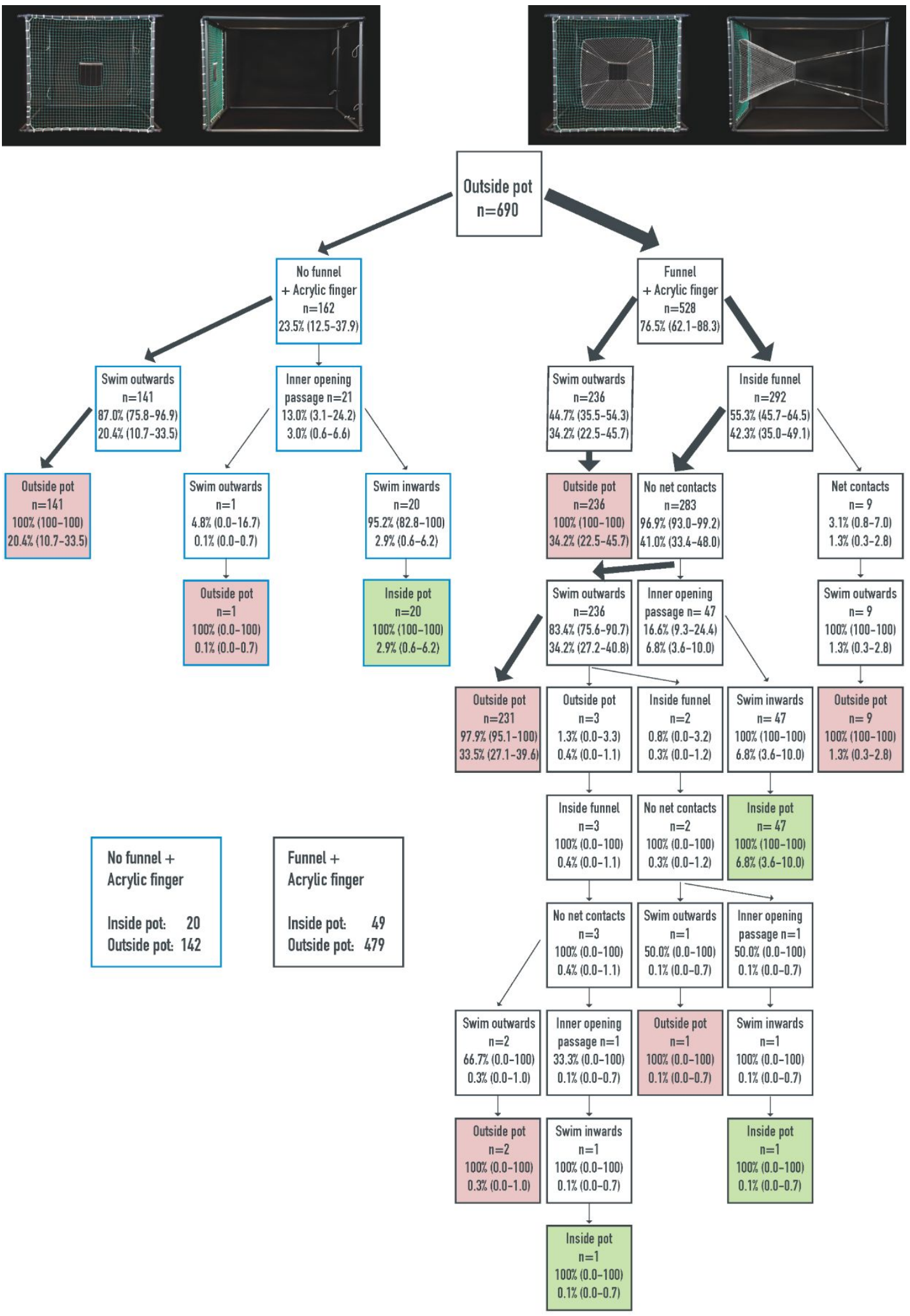

Figure 12. Behavioural event-chain tree comparing the Fun+AF entrance (control) with the NoFun+AF entrance (test) for interactions of cod with pot entrances starting outside. Each box represents an event type; the first line = event type name; the second line $=$ number of times this event was observed at this point in the event chain; the third line $=$ the marginal probabilities (MP) related to the total number of interactions; the last line = the conditional probabilities (CP) related to the number of interactions in the parent link (the link above a respective link). Confidence intervals are based on 1000 bootstrap iterations. 

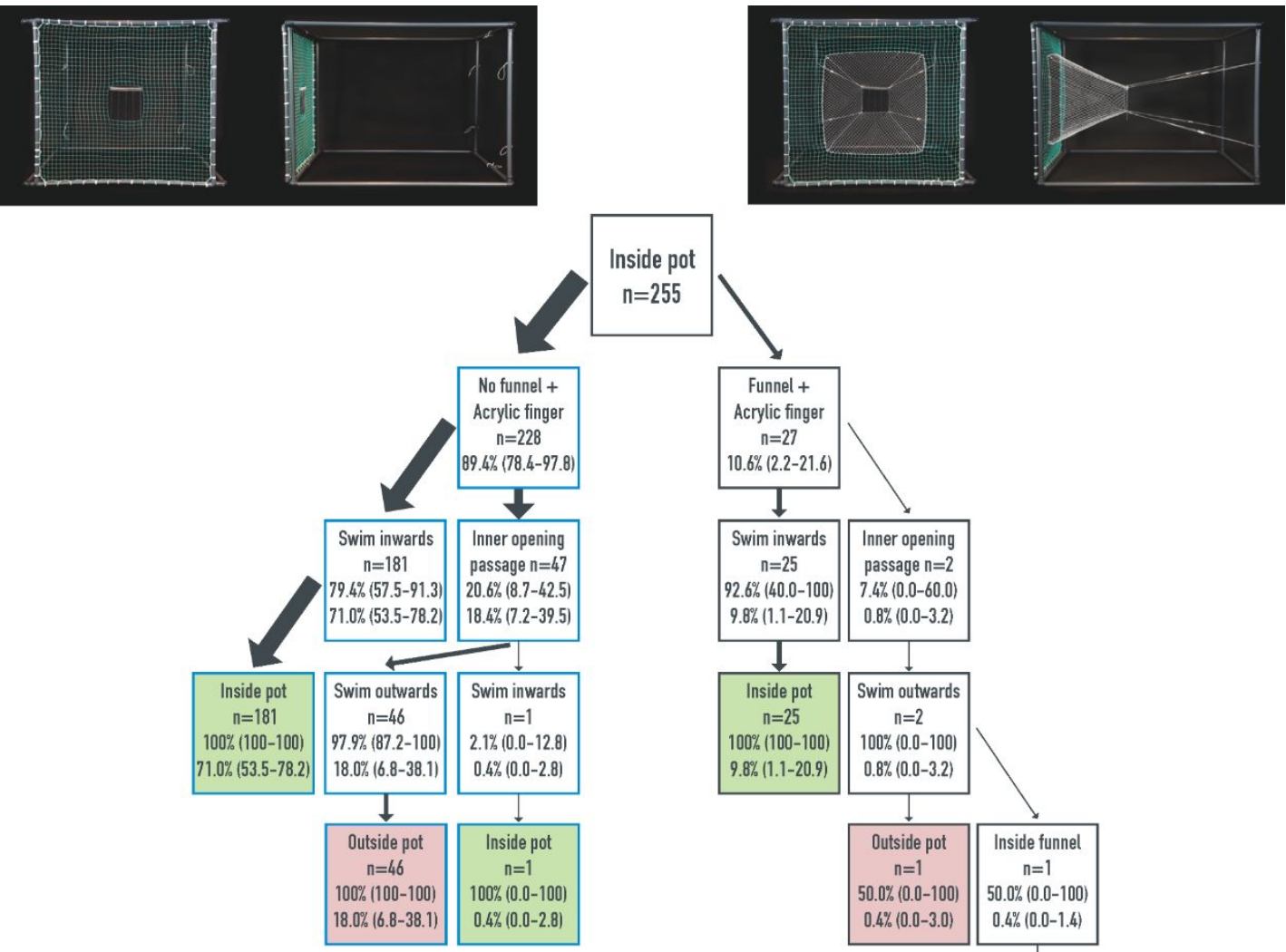

No funnel +
Acrylic finger
Inside pot: 182
Outside pot: 46

Funnel +
Acrylic finger
Inside pot: 25
Outside pot: 2

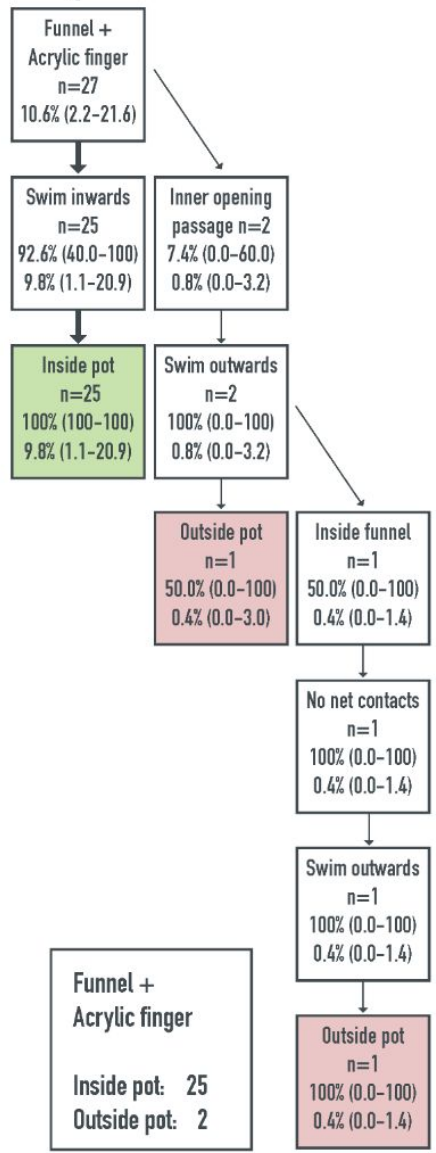

Figure 13. Behavioural event-chain tree comparing the Fun+AF entrance (control) with the NoFun+AF entrance (test) for interactions of cod with pot entrances starting outside. Each box represents an event type; the first line = event type name; the second line = number of times this event was observed at this point in the event chain; the third line = the marginal probabilities (MP) related to the total number of interactions; the last line = the conditional probabilities (CP) related to the number of interactions in the parent link (the link above a respective link). Confidence intervals are based on 1000 bootstrap iterations.

No Funnel+acrylic fingers vs. No Funnel+Neptune fingers entrance

We compared the NoFun+AF and the NoFun+NF entrances in two replicates. The NoFun+AF was set as control $(p(I / O=0))$. The final entry model included only the intercept. There were significantly fewer entries through the NoFun+NF. The behavioural analysis tree reveals that this was caused by significantly fewer approaches to the NoFun+NF (Figure 14). There were no exits through the NoFun+NF and seven exits through the AF. All cod in this experiment were in the $30-39 \mathrm{~cm}$ length class. All cod exiting through the NoFun+AF seemed able to pass between two fingers without touching them. Nonetheless, $88.5 \%$ of all inside approaches to the NoFun+AF were aborted, indicating that the NoFun+AF still had an exit-impeding effect (Figure 15). 

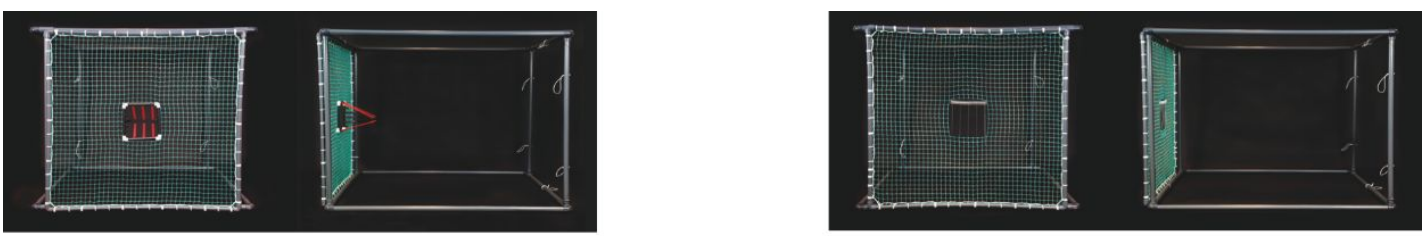

464 Figure 14. Behavioural event-chain tree comparing the NoFun+AF entrance (control) with the NoFun+NF entrance (test) 465 for interactions of cod with pot entrances starting outside. Each box represents an event type; the first line = event type 466 name; the second line = number of times this event was observed at this point in the event chain; the third line = the 467 marginal probabilities (MP) related to the total number of interactions; the last line = the conditional probabilities (CP) 468 related to the number of interactions in the parent link (the link above a respective link). Confidence intervals are based 469 on 1000 bootstrap iterations. 

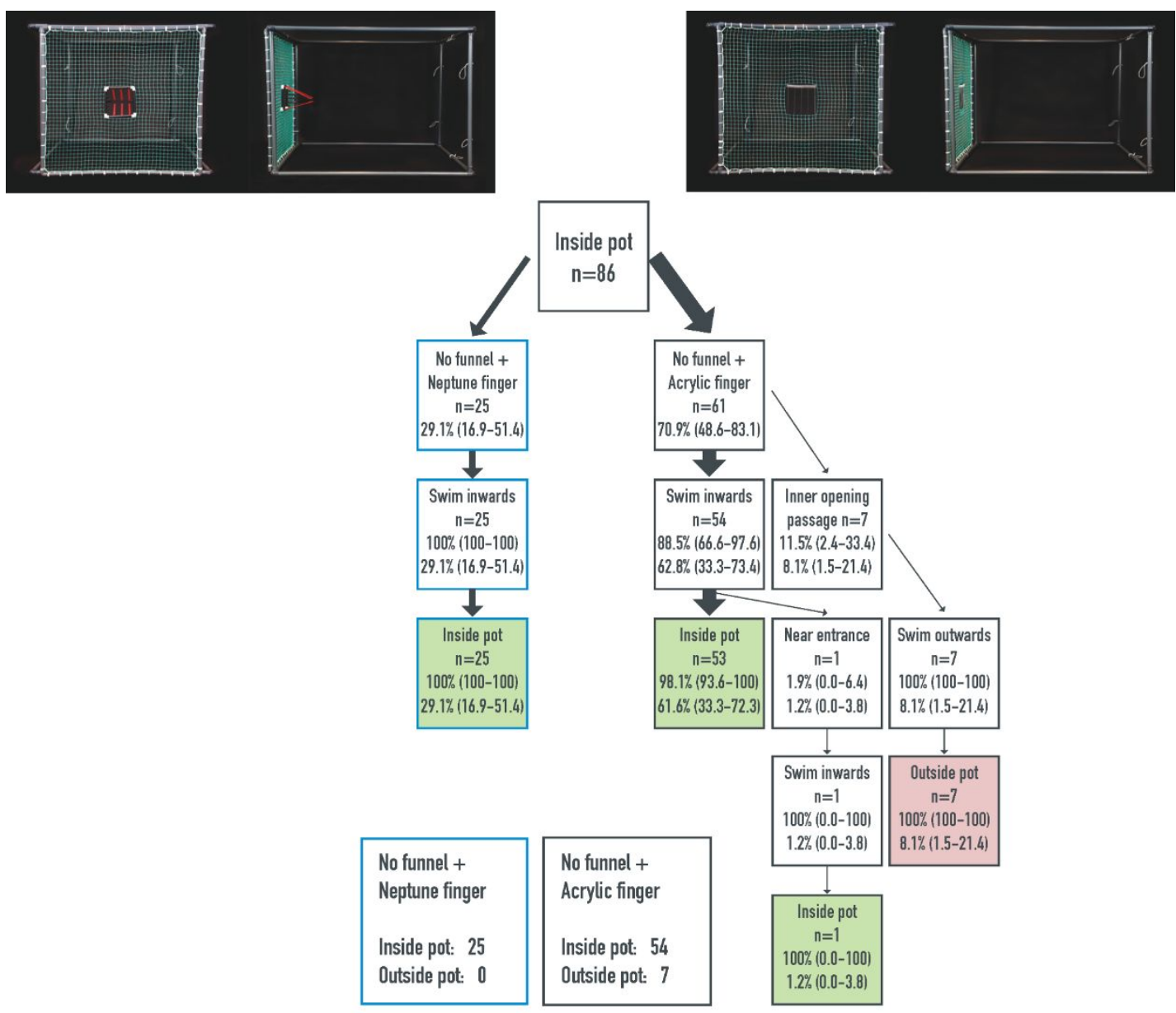

Figure 15. Behavioural event-chain tree comparing the NoFun+AF entrance (Control) with the NoFun+NF entrance (Test) for interactions of cod with pot entrances starting inside. Each box represents an event type; the first line = event type name; the second line $=$ number of times this event was observed at this point in the event chain; the third line $=$ the marginal probabilities (MP) related to the total number of interactions; the last line = the conditional probabilities (CP) related to the number of interactions in the parent link (the link above a respective link). Confidence intervals are based on 1000 bootstrap iterations.

\section{Discussion}

For this study, we developed and tested an innovative new trigger FRD concept, which we named acrylic fingers (AF), that makes use of the near invisibility of acrylic glass underwater and a density similar to seawater. We avoided the drawback of other FRDs, which may deter fish owing to their distinct visual outline and the physical resistance other FRDs present to fish entering the pot. We compared the AFs with commercially available NFs, and demonstrated that NFs have a strong deterrent effect. Adding NFs to a funnel reduced catch efficiency from 0.250 to 0.204 , whereas adding AFs to the same funnel entrance almost doubled catch efficiency to 0.446 . Therefore, AFs might support the uptake of the environmentally favourable fish pots in fisheries.

FRDs are typically described as reducing escape rates, but inevitably also reducing entry rates (e.g. Furevik and Løkkeborg, 1994; High and Ellis, 1973; Munro, 1972; Olsen, 2014). In contrast, we found no evidence that AFs reduced fish-entry rates. To our knowledge, the present study is the first to demonstrate an FRD that does not significantly decrease entry rates compared with the same entrance without an FRD. The AFs performed significantly better than the NFs in direct comparisons. Nonetheless, cod exited through the AF entrances in five of the 13 trials. Four of the trials with exiting cod involved the smallest cod length class $(30-39 \mathrm{~cm})$, and cod were able to pass between two fingers. This is not necessarily a negative result, because providing a pot-escapement 
opportunity for small cod increases fishing efficiency for larger cod (Ovegård et al., 2011) in addition to reducing bycatch of cod smaller than MCRS. However, in one trial, larger cod ( $40-49 \mathrm{~cm}$; i.e. larger than MCRS) also exited through the AF entrance by physically pushing two adjacent fingers sideways, which demonstrates further improvement potential. Possible improvements include: reducing interfinger width, increasing the AFs' thickness to reduce their flexibility, and stiffening the fingers to prevent wobbling. The AFs could be further integrated into a holding frame by fixing brackets to the inner bottom side into which the AF's fingertips could be held in place when lowered, preventing lateral movement of the fingers. Therefore, the AF, as well as other trigger-type FRDs, could also be used as selection devices, expanding the selection options of pots by using them in conjunction with selection windows. Moreover, selection windows could be replaced by size-selective triggers, which could increase pot versatility. Changing the target species and/or size would then require only changing the trigger configuration (e.g. more or less inter-finger width of triggers) or the pot entrance, and without additionally changing the selection window.

The use of both funnels and triggers synergistically improved pot-catch efficiency: Only two of the 55 exits through AFs were through the AFs attached to the white funnel. All others took place through AFs attached to the NoFun opening. In Experiment 4, Fun+AF performed significantly better for entries as well as for exits than the NoFun+AF entrance. This was the result of a significantly higher approach probability of cod to the Fun+AF from outside and a significantly lower approach probability for cod inside the pot. Considering that many cod do not enter a pot because they fail to find the entrance (e.g. Hedgärde et al., 2016; Meintzer et al., 2017), this funnel effect could be the result of the outer opening size being nine times larger than the NoFun opening, thus increasing contact probability for approaching cod.

The deterring effect of NFs appears to be caused by its distinct visual outline. Nevertheless, the shape of both FRDs also differed (AFs are curtain-shaped, similar to a cat door, whereas the NFs are funnel-shaped), which may also influence catch efficiency. However, cod rarely touched either trigger before either passing or turning around, indicating that a possible shape effect is probably limited. The only NF passage from the inside was observed at night, when a cod apparently swam inadvertently into a gap between two fingers. Before bumping back into the triggers and passing it again towards the pot inside, it moved chaotically inside the funnel, bumping several times into the netting. This is in line with observations of cod interacting with steel pot triggers: Most of the cod turning away from the triggers did so without touching the triggers (Olsen, 2014). Trigger detection and inspection are thus primarily visually mediated. In contrast to the NFs, the AFs work because of their inconspicuousness by not affecting approach probability to the entrance while still physically blocking exits.

Carlile's et al. (1997) findings could indicate that Pacific cod are less reluctant to pass entrances that they have to push through physically. However, the mean size of Pacific cod fished in the different pot types ranged from 58.7 to $62.3 \mathrm{~cm}$, considerably larger than the Atlantic cod in this study. Possibly, larger Atlantic cod could also be less reluctant to enter NFs because large cod have been observed to be less hesitant to contact and push steel triggers inwards to enter a pot (Olsen, 2014). It seems plausible that larger cod would be even less deterred by transparent AF. Additionally, they would increase visibility of the pot inside, including the pot bait, usually hung in front of the entrance (e.g. Furevik et al., 2008; Meintzer et al., 2017), which could be even more important when a bait light is used (Bryhn et al., 2014; Humborstad et al., 2018).

In addition to the necessary improvements described above, the AFs probably need further testing and development cycles. This study's tests were short and in a controlled environment. The construction of AFs is not as robust as that of the commercially field-tested NFs and probably will not sustain prolonged fishing under demanding commercial fishing conditions. Because the AFs' near 
542 invisibility underwater is the result of its favourable refractive index, algal overgrowth and scratches 543 accumulating on its surface could reduce its effectiveness over time. Technological improvement in 544 these areas could increase long-term AF effectiveness. In any case, AFs will have to be cleaned or replaced after a certain time. Prolonged field tests, best under the conditions of commercial fisheries, are thus warranted. Another study using the same experimental setup found that cod movement through funnels increases when transparent funnel netting is used instead of white netting (Chladek et al., in prep.). Therefore, AF effectiveness could be increased further by using transparent funnel netting. Furthermore, we tested only one kind of transparent trigger; other transparent trigger types could be just as, or even more, efficient. In summary, AFs or other transparent triggers can improve cod-pot catch rates considerably. In addition, they have greater development potential for even larger increases in catch efficiency, furthering the uptake of pots.

553

554

555

556

557

558

559

560

561

562

563

564

565

566

567

568

569

570

571

572

573

574

575

576

577

578

579

580

581

582

583

584

585

586

587

588

\section{Acknowledgements}

This study depended on the highly committed efforts of many dedicated colleagues who took part in developing and running the experiments. Therefore, we especially thank Lily Bovim, Ulf Böttcher, Bodo Dolk, Johanna Ferretti, Ina Hennings, Aurélien Keller, and Rainer Stechert for their support during development, set up, and running of the experiments. Furthermore, we thank Ulf Böttcher, Ashkan Daneshpour, Rainer Stechert, and Wanda Witte for video analysis, and Annemarie Schütz for figure illustrations. We thank Johanna Ferretti for reviewing the manuscript and providing helpful comments.

The study was funded by the German Federal Agency for Nature Conservation (Bundesamt für Naturschutz, project no. 3516821300, Entwicklung von alternativen Managementansätzen und Fangtechniken zur Minimierung der Konflikte zwischen Stellnetzfischerei und Naturschutzzielen in der deutschen AWZ der Ostsee - STELLA).

\section{References}

Allison, P. D. 2008. Convergence Failures in Logistic Regression. In SAS Conference Proceedings: SAS Global Forum 2008, p. 11.

Anders, N., Fernö, A., Humborstad, O.-B., Løkkeborg, S., and Utne-Palm, A. C. 2016. Species specific behaviour and catchability of gadoid fish to floated and bottom set pots. ICES Journal of Marine Science: Journal du Conseil: fsw200.

Anders, N., Fernö, A., Humborstad, O.-B., Løkkeborg, S., Rieucau, G., and Utne-Palm, A. C. 2017. Sizedependent social attraction and repulsion explains the decision of Atlantic cod Gadus morhua to enter baited pots. Journal of fish biology, 91: 1569-1581.

Austin, R. W., and Halikas, G. 1976. The Index of Refraction of Seawater: Defense Technical Information Center, Fort Belvoir, VA. http://www.dtic.mil/docs/citations/ADA024800 (Accessed 8 June 2020).

Bryhn, A. C., Königson, S., Lunneryd, S.-G., and Bergenius, M. A. J. 2014. Green lamps as visual stimuli affect the catch efficiency of floating cod (Gadus morhua) pots in the Baltic Sea. Fisheries Research, 157: 187-192.

Carlile, D. W., Dinnocenzo, T. A., and Watson, L. J. 1997. Evaluation of modified crab pots to increase catch of Pacific cod and decrease bycatch of Pacific halibut. North American Journal of Fisheries Management, 17: 910-928.

Chladek, J., Kratzer, I. M. F., Ljungberg, P., Svendsen, J. C., Hermann, A., Santos, J., and Stepputis, D. in prep. Preliminary title: Insight s into cod-pot entrance interactions and diurnal catch process influence through innovative net pen based observation concept.

EP, (European Parliament), and EU Council, (Council of the European Unino). 2013. Regulation (EU) No $1380 / 2013$ on the Common Fisheries Policy, amending Council Regulations (EC) No $1954 / 2003$ and (EC) No 1224/2009 and repealing Council Regulations (EC) No 2371/2002 and 
(EC) No 639/2004 and Council Decision 2004/585/EC. Official Journal of the European Union, REGULATION (EU) No 1380/2013. Strasbourg.

Friard, O., and Gamba, M. 2016. BORIS: a free, versatile open-source event-logging software for video/audio coding and live observations. Methods in Ecology and Evolution, 7: 1325-1330.

Furevik, D. M. 1994. Behaviour of fish in relation to pots. In Marine fish behaviour in capture and abundance estimation, pp. 22-44. Ed. by A. Fernö and S. Olsen. Fishing News Books, Oxford.

Furevik, D. M., and Løkkeborg, S. 1994. Fishing trials in Norway for torsk (Brosme brosme) and cod (Gadus morhua) using baited commercial pots. Fisheries Research, 19: 219-229.

Furevik, D. M., and Hågensen, S. 1997. Experiments of cod pots as an alternative to gillnets in the Varanger Fjord in April-June and October-December 1996. In pp. 121-132. Murmansk.

Furevik, D. M., Humborstad, O.-B., Jørgensen, T., and Løkkeborg, S. 2008. Floated fish pot eliminates bycatch of red king crab and maintains target catch of cod. Fisheries research, 92: 23-27.

Gilman, E., Brothers, N., and Kobayashi, D. R. 2005. Principles and approaches to abate seabird bycatch in longline fisheries. Fish and Fisheries, 6: 35-49.

Gilman, E., Zollett, E., Beverly, S., Nakano, H., Davis, K., Shiode, D., Dalzell, P., et al. 2006. Reducing sea turtle by-catch in pelagic longline fisheries. Fish and Fisheries, 7: 2-23.

Gilman, E. 2015. Status of international monitoring and management of abandoned, lost and discarded fishing gear and ghost fishing. Marine Policy, 60: 225-239.

Grabowski, J. H., Bachman, M., Demarest, C., Eayrs, S., Harris, B. P., Malkoski, V., Packer, D., et al. 2014. Assessing the Vulnerability of Marine Benthos to Fishing Gear Impacts. Reviews in Fisheries Science \& Aquaculture, 22: 142-155.

Halpern, B. S., Walbridge, S., Selkoe, K. A., Kappel, C. V., Micheli, F., D’Agrosa, C., Bruno, J. F., et al. 2008. A Global Map of Human Impact on Marine Ecosystems. Science, 319: 948-952. American Association for the Advancement of Science.

Hardie, D. C., and Hutchings, J. A. 2011. The Ecology of Atlantic Cod (Gadus morhua) in Canadian Arctic Lakes. ARCTIC, 64: 137-150.

Hedgärde, M., Berg, C. W., Kindt-Larsen, L., Lunneryd, S.-G., and Königson, S. 2016. Explaining the catch efficiency of different cod pots using underwater video to observe cod entry and exit behaviour. Journal of Ocean Technology, 11: 67-90.

Hermann, A., Chladek, J., and Stepputis, D. submitted. iFO - an open source low-cost infrared fish observation system. Submitted to Hardware X 20. June 2020.

High, W. L., and Ellis, I. E. 1973. Underwater observations of fish behavior in traps. Helgoländer Wissenschaftliche Meeresuntersuchungen, 24: 341.

Humborstad, O.-B., Breen, M., Davis, M. W., Løkkeborg, S., Mangor-Jensen, A., Midling, K. $\varnothing$., and Olsen, R. E. 2016. Survival and recovery of longline- and pot-caught cod (Gadus morhua) for use in capture-based aquaculture (CBA). Fisheries Research, 174: 103-108.

Humborstad, O.-B., Utne-Palm, A. C., Breen, M., and Løkkeborg, S. 2018. Artificial light in baited pots substantially increases the catch of cod (Gadus morhua) by attracting active bait, krill (Thysanoessa inermis). ICES Journal of Marine Science, 75: 2257-2264.

Jørgensen, T., Løkkeborg, S., Furevik, D., Humborstad, O.-B., and De Carlo, F. 2017. Floated cod pots with one entrance reduce probability of escape and increase catch rates compared with pots with two entrances. Fisheries Research, 187: 41-46.

Lewison, R. L., Crowder, L. B., Wallace, B. P., Moore, J. E., Cox, T., Zydelis, R., McDonald, S., et al. 2014. Global patterns of marine mammal, seabird, and sea turtle bycatch reveal taxa-specific and cumulative megafauna hotspots. Proceedings of the National Academy of Sciences, 111: 5271-5276.

Ljungberg, P., Lunneryd, S.-G., Lövgren, J., and Königson, S. 2016. Including cod (Gadus morhua) behavioural analysis to evaluate entrance type dependent pot catch in the Baltic Sea. Journal of Ocean Technology, 11: 48-63.

Malitson. 1965. Optical constants of Fused silica (fused quartz). refractiveindex.info (Accessed 20 June 2018). 
640

641

642

643

644

645

646

647

648

649

650

651

652

653

654

655

656

657

658

659

660

661

662

663

664

665

666

667

668

669

670

671

672

673

674

675

676

677

678

679

680

681

Meager, J. J., Domenici, P., Shingles, A., and Utne-Palm, A. C. 2006. Escape responses in juvenile Atlantic cod Gadus morhua L.: the effects of turbidity and predator speed. Journal of Experimental Biology, 209: 4174-4184.

Meintzer, P., Walsh, P., and Favaro, B. 2017. Will you swim into my parlour? In situ observations of Atlantic cod (Gadus morhua) interactions with baited pots, with implications for gear design. PeerJ, 5: e2953.

Meintzer, P., Walsh, P., and Favaro, B. 2018. Comparing catch efficiency of five models of pot for use in a Newfoundland and Labrador cod fishery. PLOS ONE, 13: e0199702.

Mieske, B. 1998. Zerlegbare Netzkäfig-Pontonrahmen Technische Entwicklung des Instituts für Ostseefischerei. Inf. Fischwirtsch., 45: 10.

Millar, R. B. 1993. Incorporation of between-haul variation using bootstrapping and. Fishery Bulletin, 91: 564-572.

Munro, J. L. 1972. Large volume stackable fish traps for offshore fishing. http://aquaticcommons.org/12082/1/gcfi_25-19.pdf (Accessed 7 August 2017).

Olsen, L. 2014. Baited pots as an alternative fishing gear in the Norwegian fishery for Atlantic cod (Gadus morhua). UiT The Arctic University of Norway.

Ovegård, M., Königson, S., Persson, A., and Lunneryd, S.-G. 2011. Size selective capture of Atlantic cod (Gadus morhua) in floating pots. Fisheries Research, 107: 239-244.

Ovegård, M., Berndt, K., and Lunneryd, S.-G. 2012. Condition indices of Atlantic cod (Gadus morhua) biased by capturing method. ICES Journal of Marine Science: Journal du Conseil: fss 145.

Santos, J., Herrmann, B., Stepputis, D., Gökçe, G., and Mieske, B. submitted. Quantifying the performance of selective devices by combining analysis of catch data and fish behaviour observations: Methodology and case study on a flatfish excluder. Submitted to ICES Journal of Marine Science 02-December-2019.

Santos, J., Herrmann, B., Mieske, B., Stepputtis, D., Krumme, U., and Nilsson, H. 2016. Reducing flatfish bycatch in roundfish fisheries. Fisheries Research, 184: 64-73.

Shester, G. G., and Micheli, F. 2011. Conservation challenges for small-scale fisheries: Bycatch and habitat impacts of traps and gillnets. Biological Conservation, 144: 1673-1681.

Suuronen, P., Chopin, F., Glass, C., Løkkeborg, S., Matsushita, Y., Queirolo, D., and Rihan, D. 2012. Low impact and fuel efficient fishing-looking beyond the horizon. Fisheries Research, 119: 135-146.

Thomsen, B., Humborstad, O.-B., and Furevik, D. M. 2010. Fish Pots: Fish Behavior, Capture Processes, and Conservation Issues. In Behavior of Marine Fishes, pp. 143-158. WileyBlackwell. http://dx.doi.org/10.1002/9780813810966.ch6.

UN, (United Nations). 2015. Transforming our World: the 2030 Agenda for Sustainable Development. A/RES/70/1. https://sustainabledevelopment.un.org/content/documents/21252030\%20Agenda\%20for\%2 OSustainable\%20Development\%20web.pdf.

Utne-Palm, A. C., Breen, M., Løkkeborg, S., and Humborstad, O. B. 2018. Behavioural responses of krill and cod to artificial light in laboratory experiments. PloS one, 13: e0190918.

Žydelis, R., Small, C., and French, G. 2013. The incidental catch of seabirds in gillnet fisheries: A global review. Biological Conservation, 162: 76-88. 
Figure 1. Above: 'Funnel' entrance (Fun hereafter; white PA funnel, $25 \mathrm{~mm}$ bar width, a $60 \times 60 \mathrm{~cm}$ outer opening and a $20 \times 20 \mathrm{~cm}$ inner opening, length $50 \mathrm{~cm}$ ) used for experiments. Left: front view; right: side view. The nomenclature describing the parts of a pot entrance is indicated on the upper side view: a) outer opening; b) funnel; c) inner opening. Below: The 'No funnel' entrance ('NoFun' hereafter). Left: front view; right: side view. Its single opening is also referred to as 'Inner opening' in the analysis. 


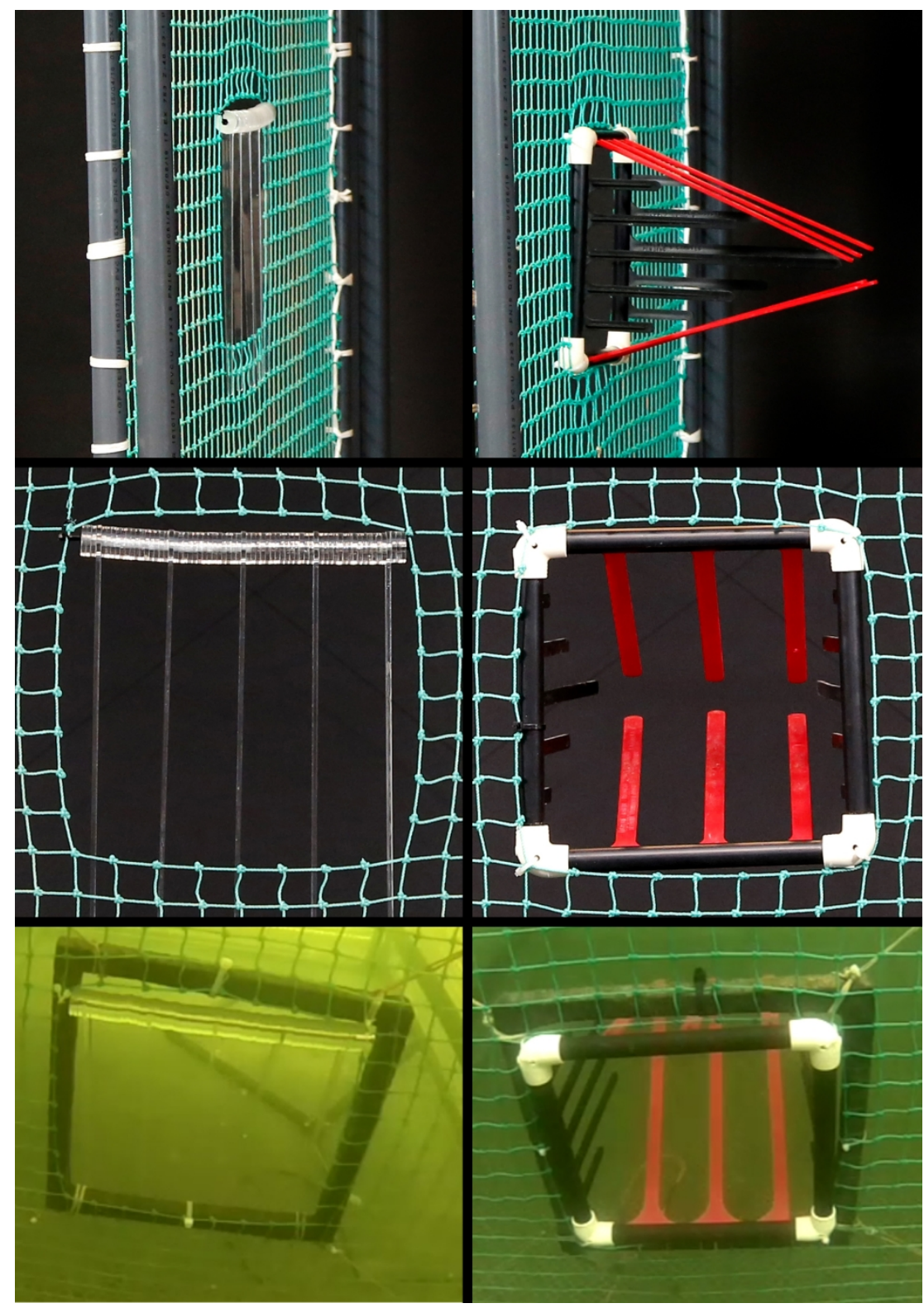

Figure 2. Acrylic fingers (AFs; left) and Neptune finger (NFs; right) attached to the NoFun entrance. First row side view in air, second row front view in air, last row front view underwater. For photos of triggers attached to the Fun entrance, see Figure appendix 5.

$563 \times 802 \mathrm{~mm}(72 \times 72 \mathrm{DPI})$ 


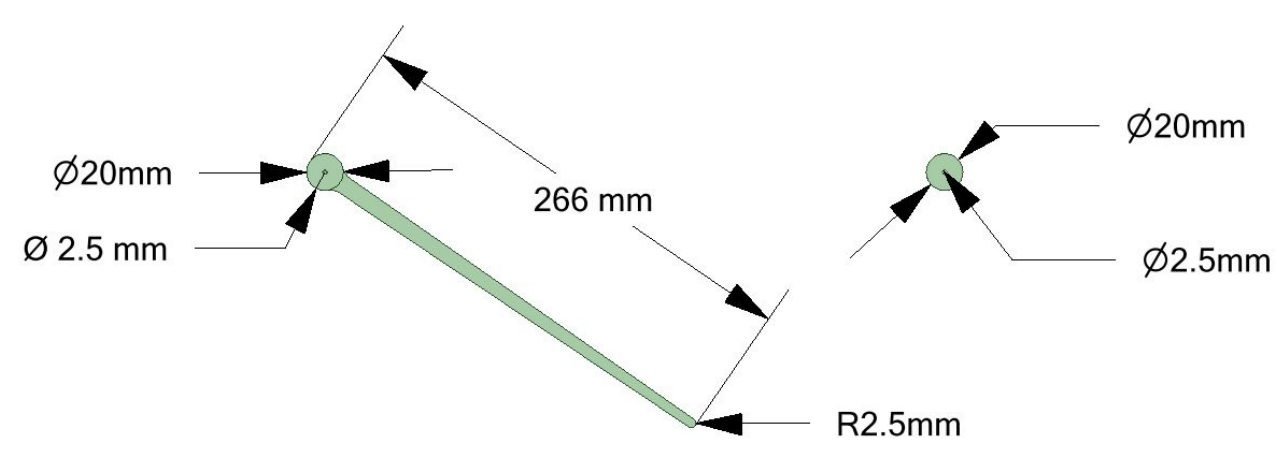

Figure 3. Dimensions of a finger of an $\mathrm{AF}$ trigger and an $\mathrm{AF}$ washer. $320 \times 122 \mathrm{~mm}(96 \times 96 \mathrm{DPI})$ 


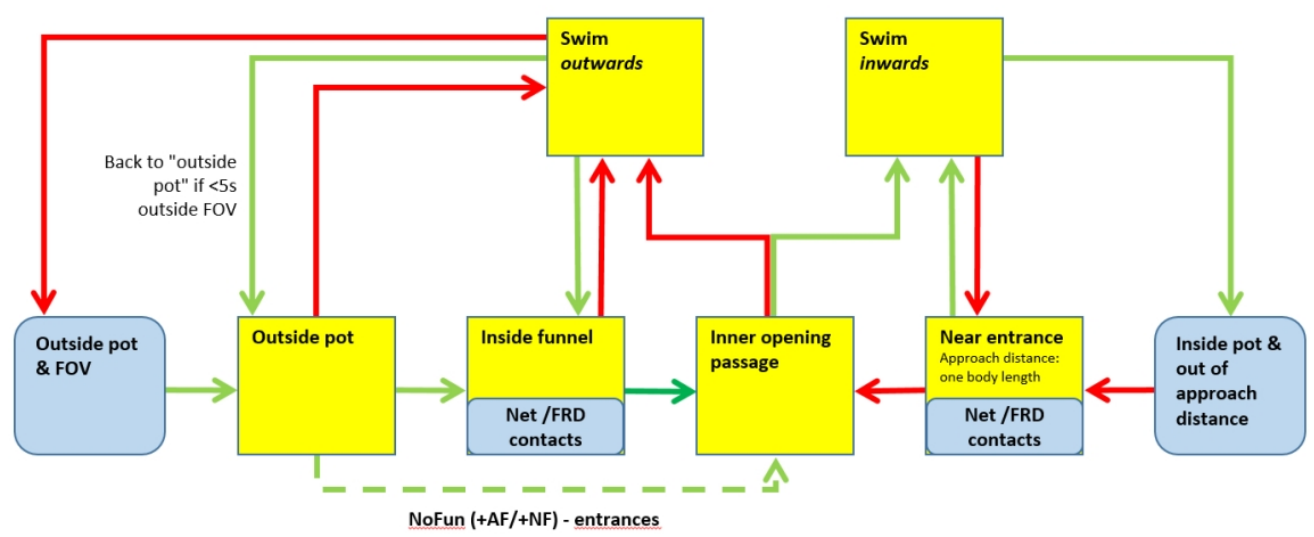

Figure 4. Behavioural flow diagram of pot-interaction event chains. Blue boxes: point events (no duration); yellow boxes: state events (with duration); bold: event type name; red: event modifier; green arrows: movements from the outside inwards; dashed green arrow: movement for NoFun+AF/NoFun+NF (both without funnel); red arrows: from inside the pot outwards. On the outside, an event chain starts or ends when a cod enters or leaves the camera FOV outside the pot (event 'Outside pot \& FOV'). On the inside, an event starts or ends when a cod approaches the inner entrance opening to within one body length or increases its distance from it to more than one body length. 


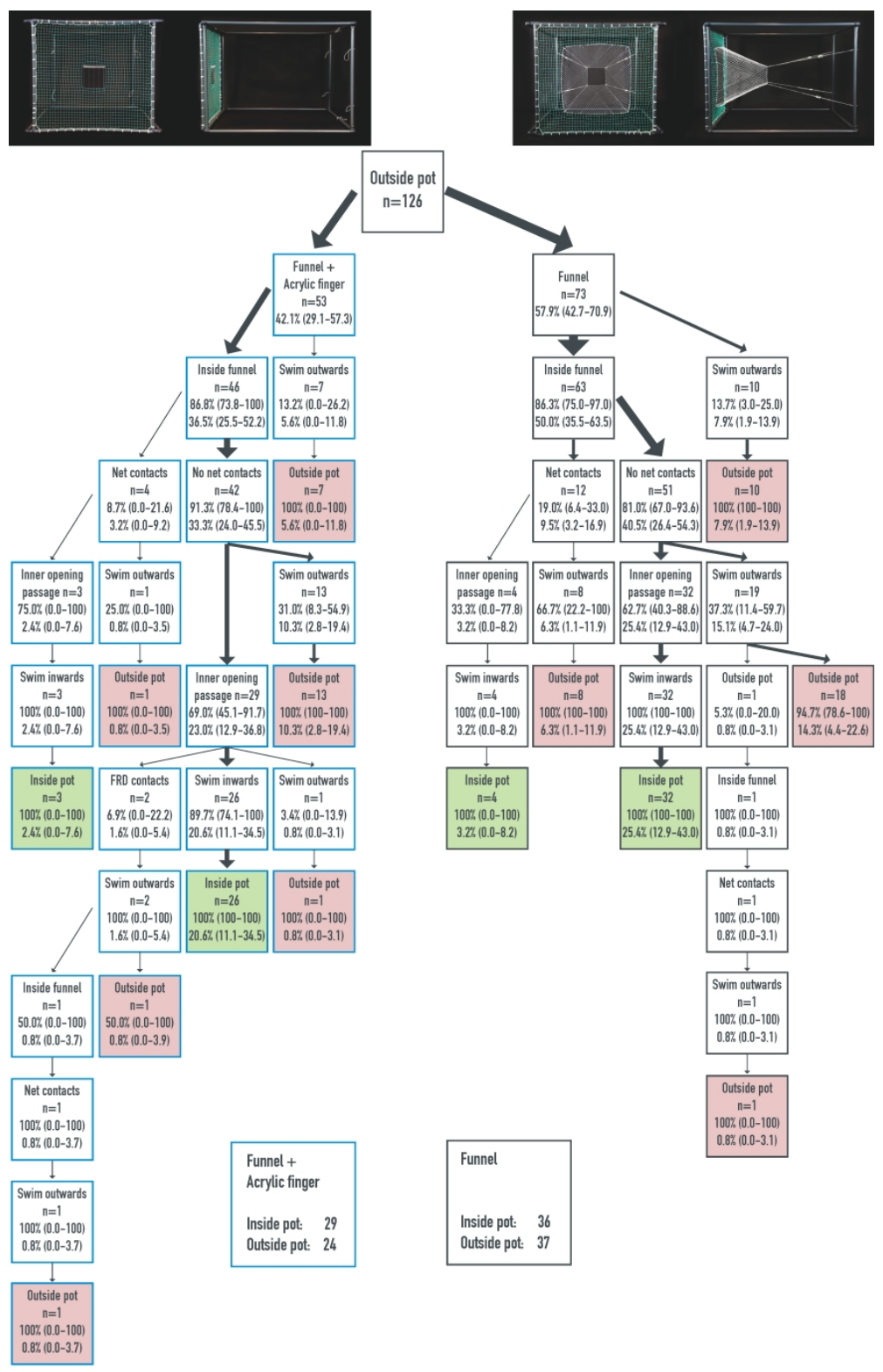

Figure 5. Behavioural event-chain tree comparing the Fun entrance (control) with the Fun+AF entrance (test) for interactions of cod with pot entrances starting outside. Each box represents an event type; the first line $=$ event type name; the second line $=$ number of times this event was observed at this point in the event chain; the third line = the marginal probabilities (MP) related to the total number of interactions; the last line $=$ the conditional probabilities (CP) related to the number of interactions in the parent link (the link above a respective link). Confidence intervals are based on 1000 bootstrap iterations. 

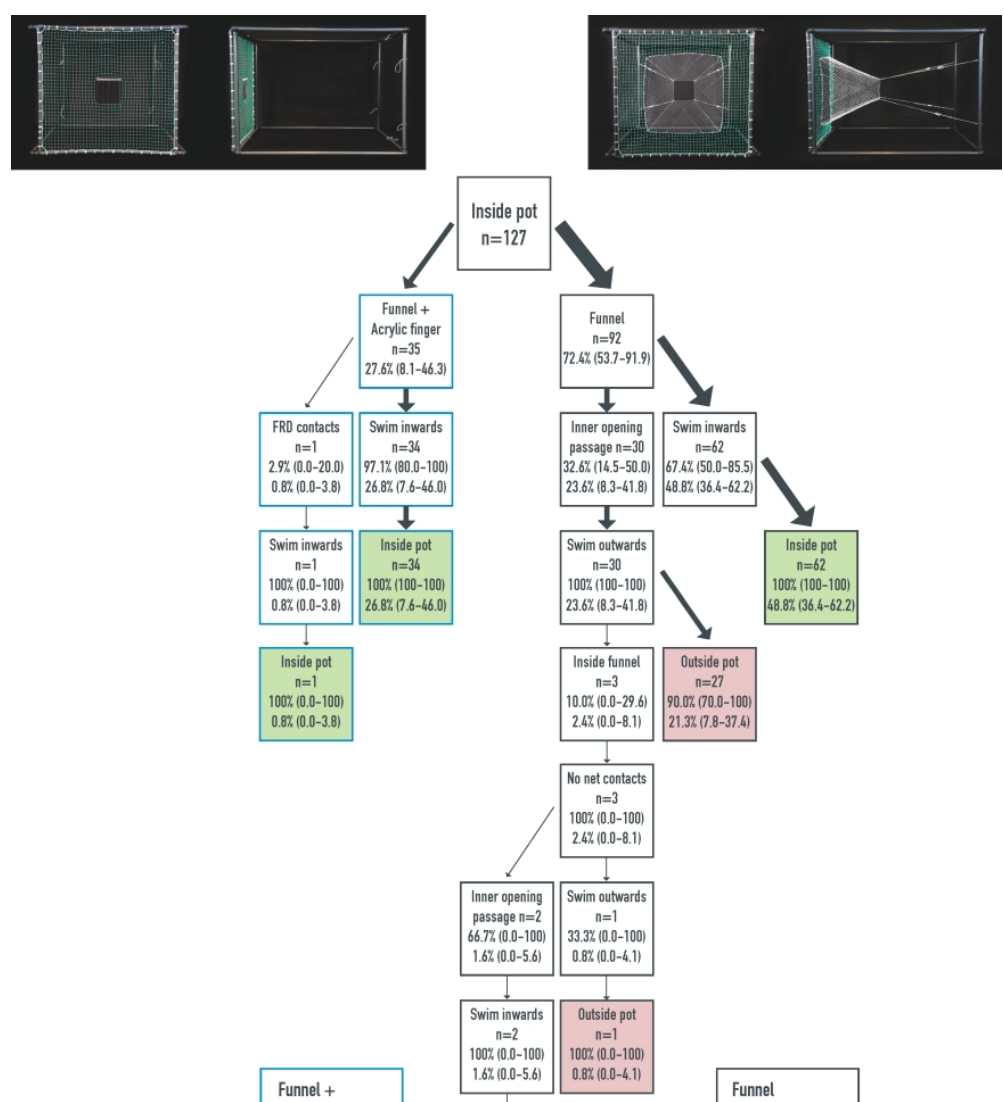

Acrylic finger

Inside pot: 35 Outside pot: 0
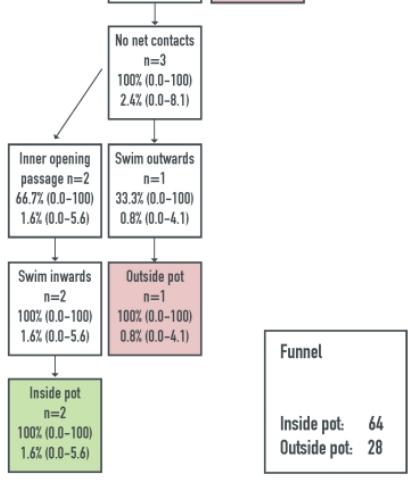

Figure 6. Behavioural event-chain tree comparing the Fun entrance (control) with the Fun+AF entrance (test) for interactions of cod with pot entrances starting inside. Each box represents an event type; the first line = event type name; the second line = number of times this event was observed at this point in the event chain; the third line = the marginal probabilities (MP) related to the total number of interactions; the last line $=$ the conditional probabilities $(\mathrm{CP})$ related to the number of interactions in the parent link (the link above a respective link). Confidence intervals are based on 1000 bootstrap iterations. 


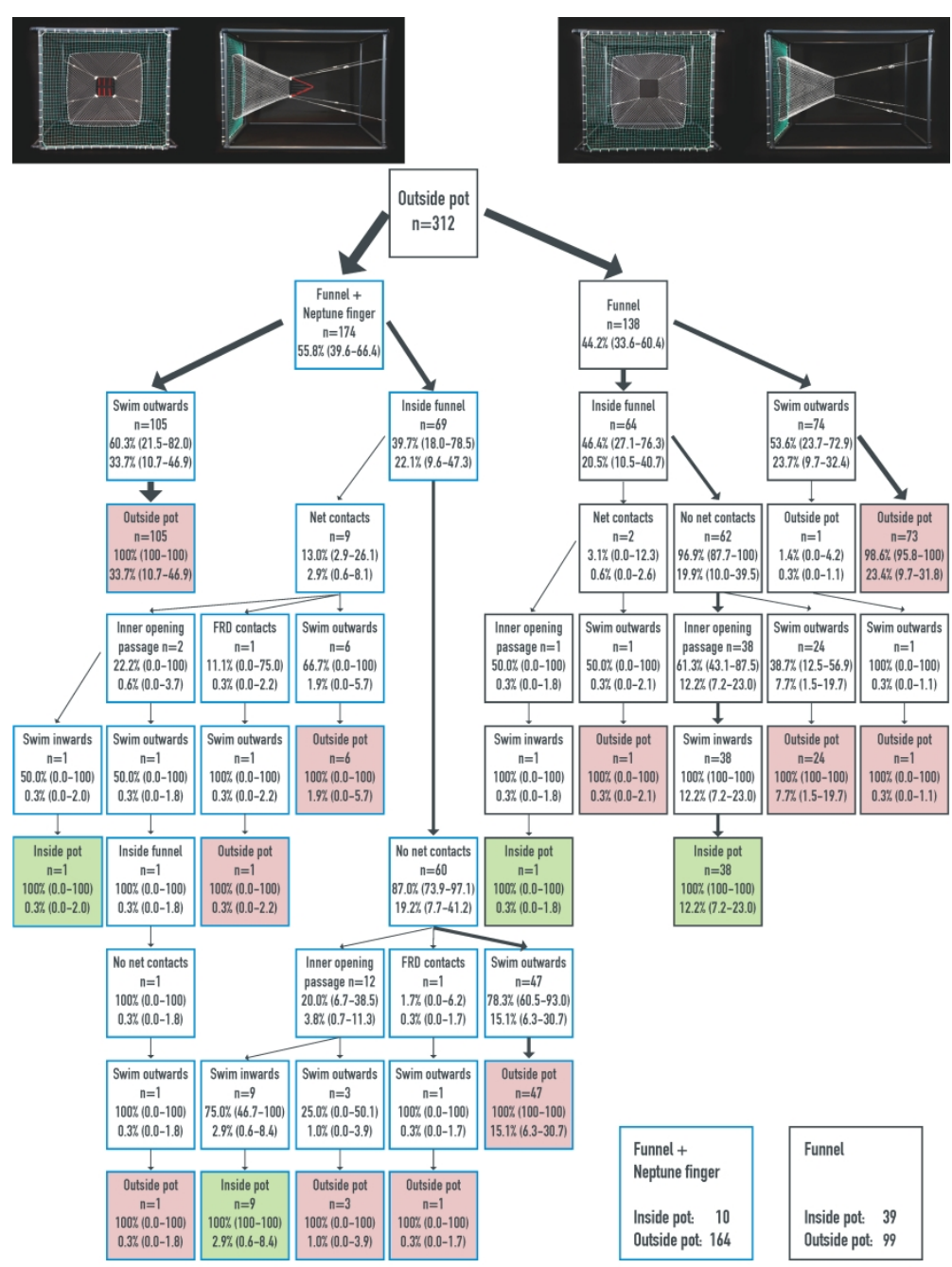

Figure 7. Behavioural event-chain tree comparing the Fun entrance (control) with the Fun+NF entrance (test) for interactions of cod with pot entrances starting outside. Each box represents an event type; the first line $=$ event type name; the second line $=$ number of times this event was observed at this point in the event chain; the third line $=$ the marginal probabilities (MP) related to the total number of interactions; the last line $=$ the conditional probabilities (CP) related to the number of interactions in the parent link (the link above a respective link). Confidence intervals are based on 1000 bootstrap iterations. 

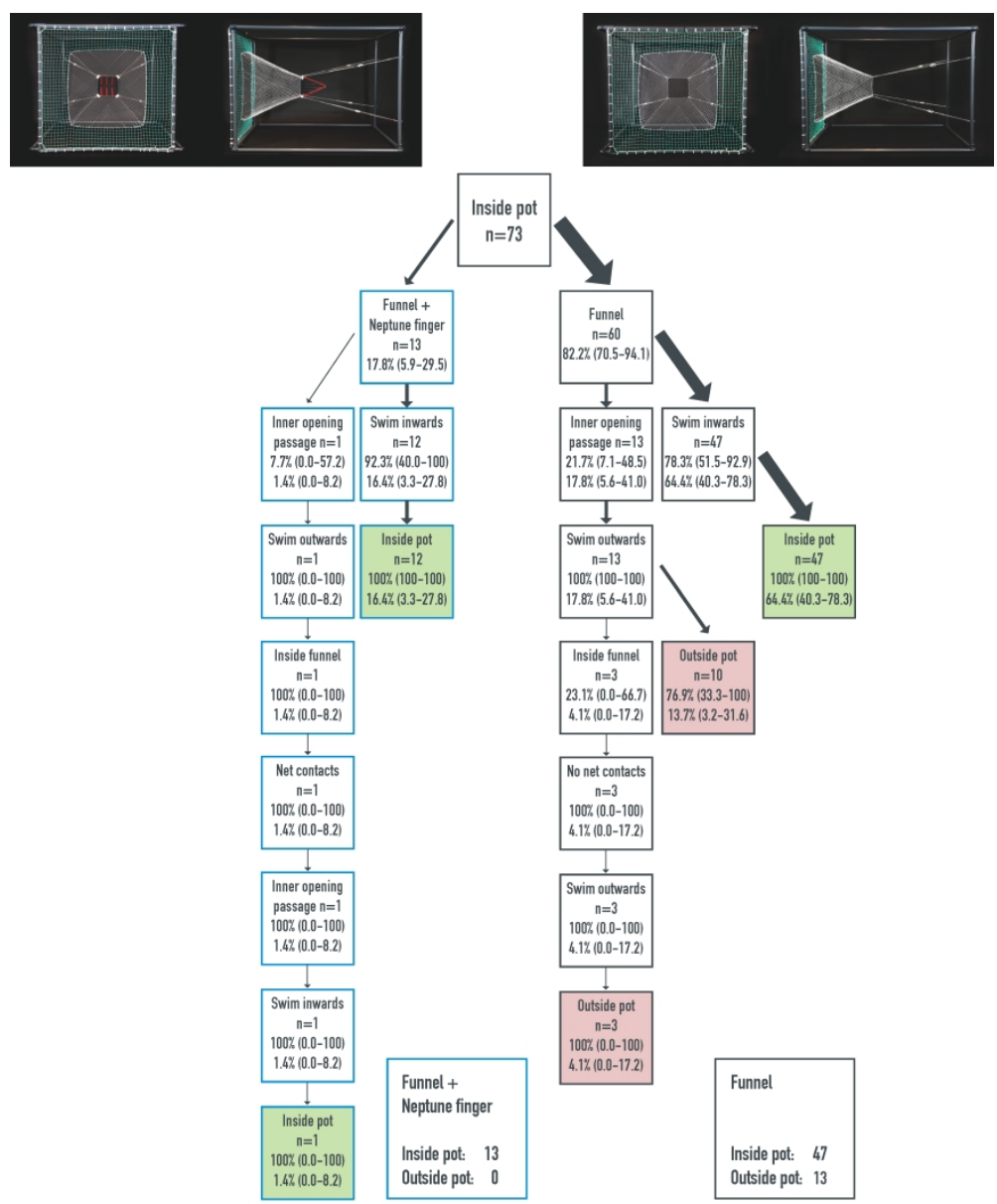

Figure 8. Behavioural event chain tree comparing the Fun entrance (control) with the Fun+NF entrance (test) for interactions of cod with pot entrances starting inside. Each box represents an event type; the first line = event type name; the second line = number of times this event was observed at this point in the event chain; the third line $=$ the marginal probabilities (MP) related to the total number of interactions; the last line $=$ the conditional probabilities (CP) related to the number of interactions in the parent link (the link above a respective link). Confidence intervals are based on 1000 bootstrap iterations. 


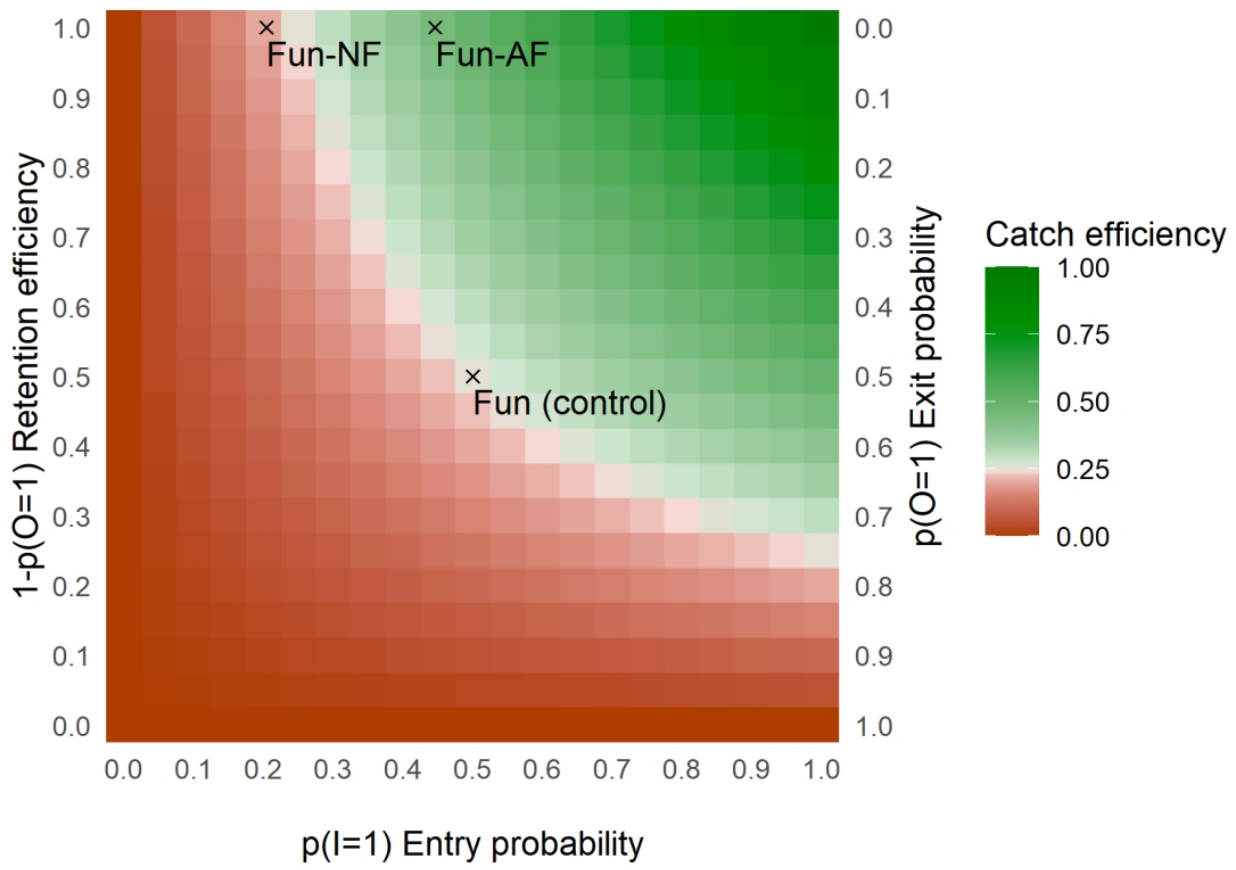

Figure 9. Catch-efficiency comparison from experiments comparing the Fun entrance (control) with the Fun+AF and Fun+NF entrances (test). 

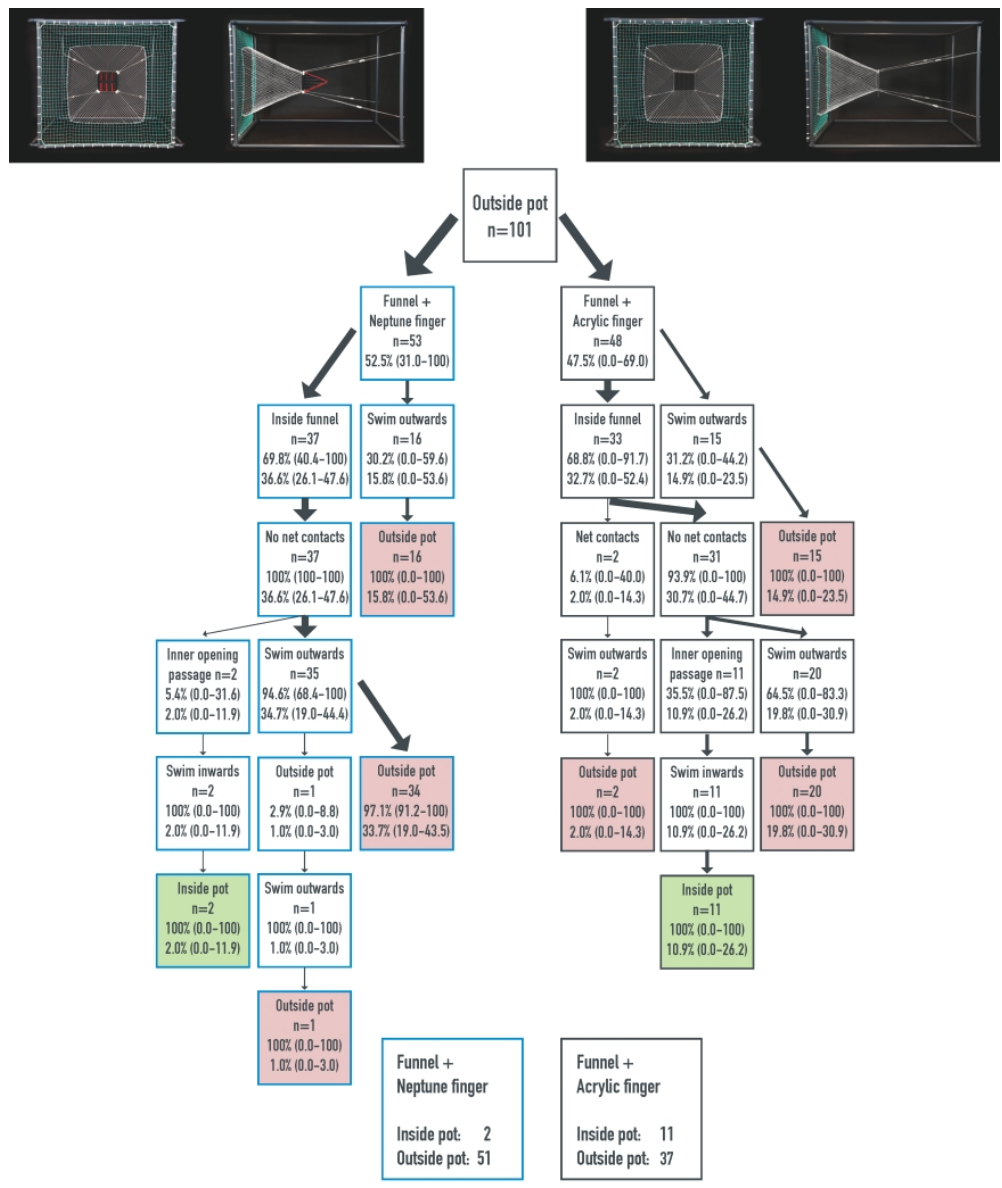

Figure 10. Behavioural event-chain tree comparing the Fun+AF entrance (control) with the Fun+NF entrance (test) for interactions of cod with pot entrances starting outside. Each box represents an event type; the first line = event type name; the second line = number of times this event was observed at this point in the event chain; the third line = the marginal probabilities (MP) related to the total number of interactions; the last line $=$ the conditional probabilities $(\mathrm{CP})$ related to the number of interactions in the parent link (the link above a respective link). Confidence intervals are based on 1000 bootstrap iterations. 

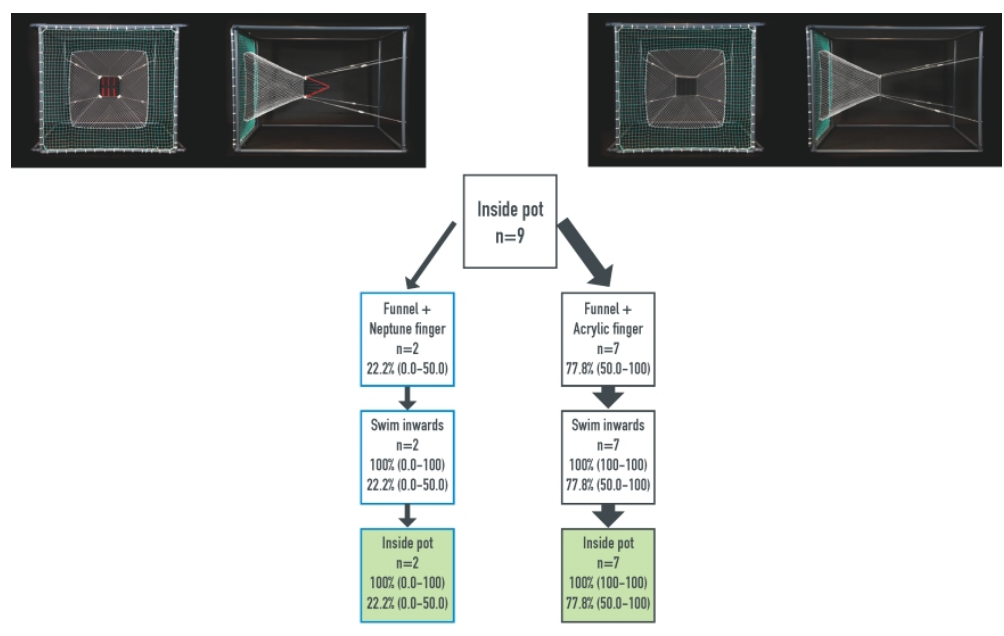

$$
\begin{array}{|l|l|}
\hline \begin{array}{ll|}
\hline \begin{array}{l}
\text { Funnel }+ \\
\text { Neptune finger }
\end{array} & \begin{array}{l}
\text { Funnel + } \\
\text { Acrylic finger }
\end{array} \\
\text { Inside pot: } & 2 \\
\text { Outside pot: } & 0
\end{array} & \begin{array}{l}
\text { Inside pot: 7 } \\
\text { Outside pot: }
\end{array} \\
\hline
\end{array}
$$

Figure 11. Behavioural event-chain tree comparing the Fun+AF entrance (control) with the Fun+NF entrance (test) for interactions of cod with pot entrances starting outside. Each box represents an event type; the first line = event type name; the second line = number of times this event was observed at this point in the event chain; the third line = the marginal probabilities (MP) related to the total number of interactions; the last line $=$ the conditional probabilities $(\mathrm{CP})$ related to the number of interactions in the parent link (the link above a respective link). Confidence intervals are based on 1000 bootstrap iterations. 

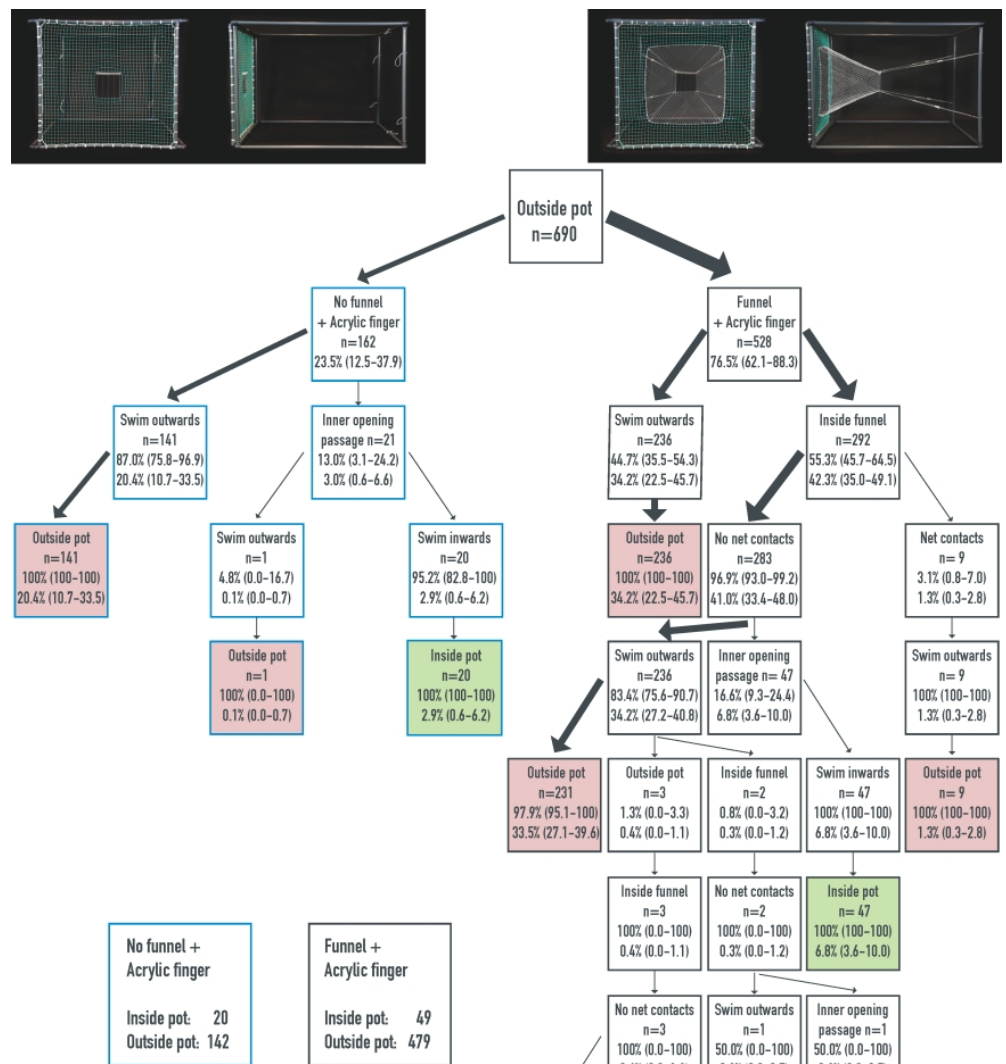

Figure 12. Behavioural event-chain tree comparing the Fun+AF entrance (control) with the NoFun+AF entrance (test) for interactions of cod with pot entrances starting outside. Each box represents an event type; the first line = event type name; the second line = number of times this event was observed at this point in the event chain; the third line = the marginal probabilities (MP) related to the total number of interactions; the last line $=$ the conditional probabilities $(\mathrm{CP})$ related to the number of interactions in the parent link (the link above a respective link). Confidence intervals are based on 1000 bootstrap iterations. 

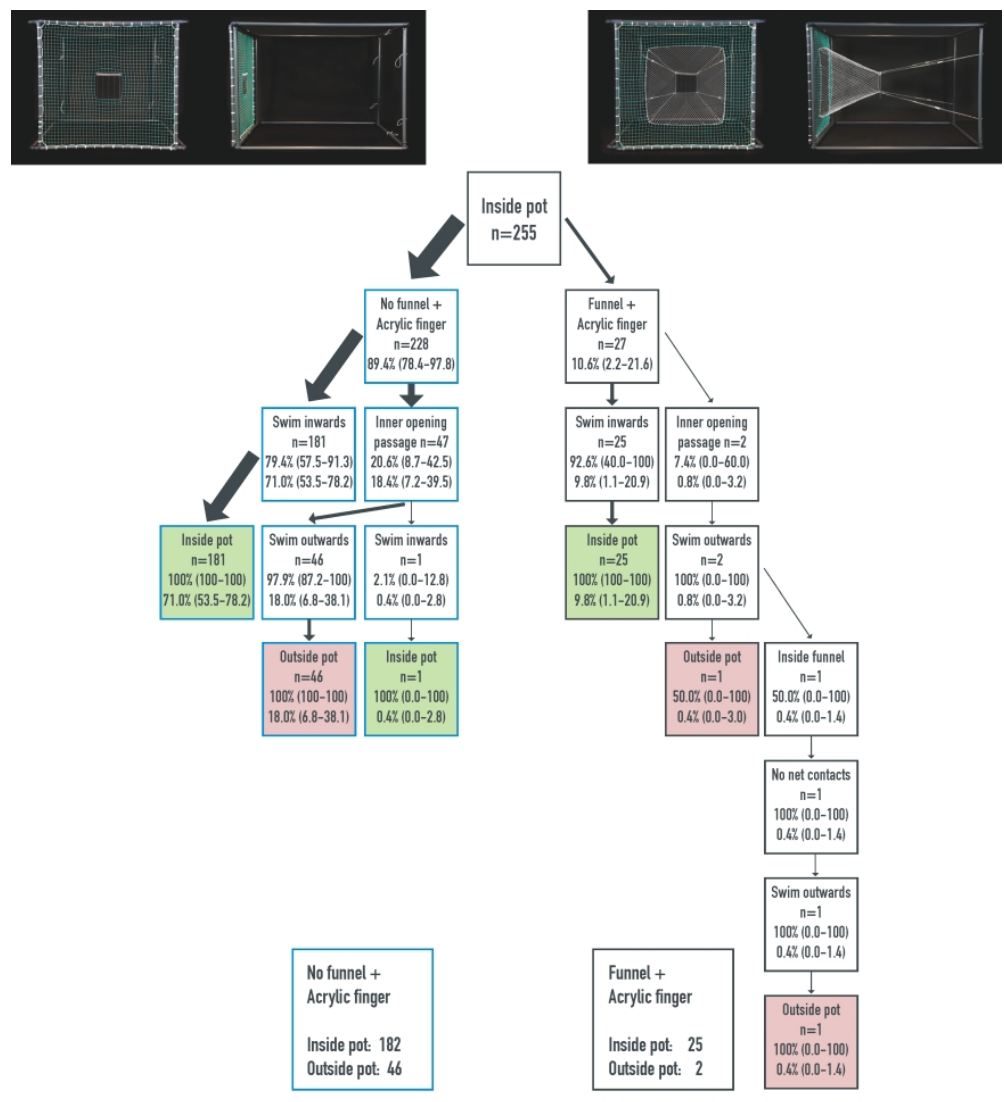

Figure 13. Behavioural event-chain tree comparing the Fun+AF entrance (control) with the NoFun+AF entrance (test) for interactions of cod with pot entrances starting outside. Each box represents an event type; the first line = event type name; the second line = number of times this event was observed at this point in the event chain; the third line = the marginal probabilities (MP) related to the total number of interactions; the last line $=$ the conditional probabilities $(\mathrm{CP})$ related to the number of interactions in the parent link (the link above a respective link). Confidence intervals are based on 1000 bootstrap iterations. 

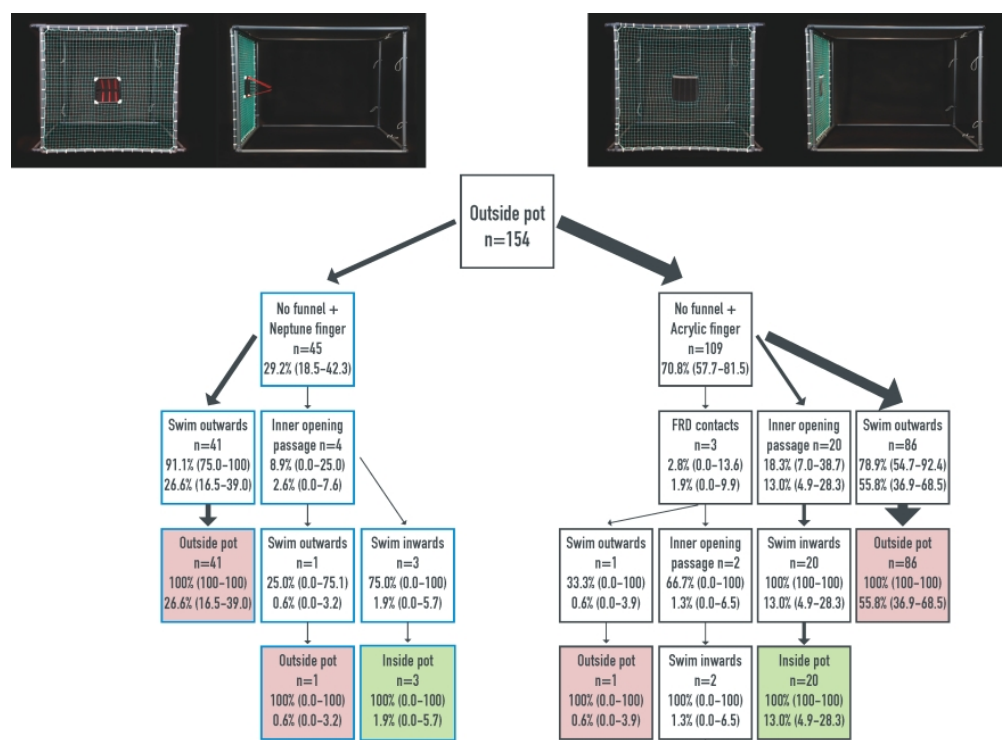

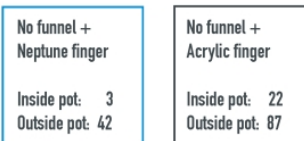$$
\begin{gathered}
\text { Inside pot } \\
n=2 \\
100 \% \text { (0.0-100) } \\
1.3 \%(0.0-6.5)
\end{gathered}
$$

Figure 14. Behavioural event-chain tree comparing the NoFun+AF entrance (control) with the NoFun+NF entrance (test) for interactions of cod with pot entrances starting outside. Each box represents an event type; the first line = event type name; the second line = number of times this event was observed at this point in the event chain; the third line = the marginal probabilities (MP) related to the total number of interactions; the last line $=$ the conditional probabilities (CP) related to the number of interactions in the parent link (the link above a respective link). Confidence intervals are based on 1000 bootstrap iterations. 

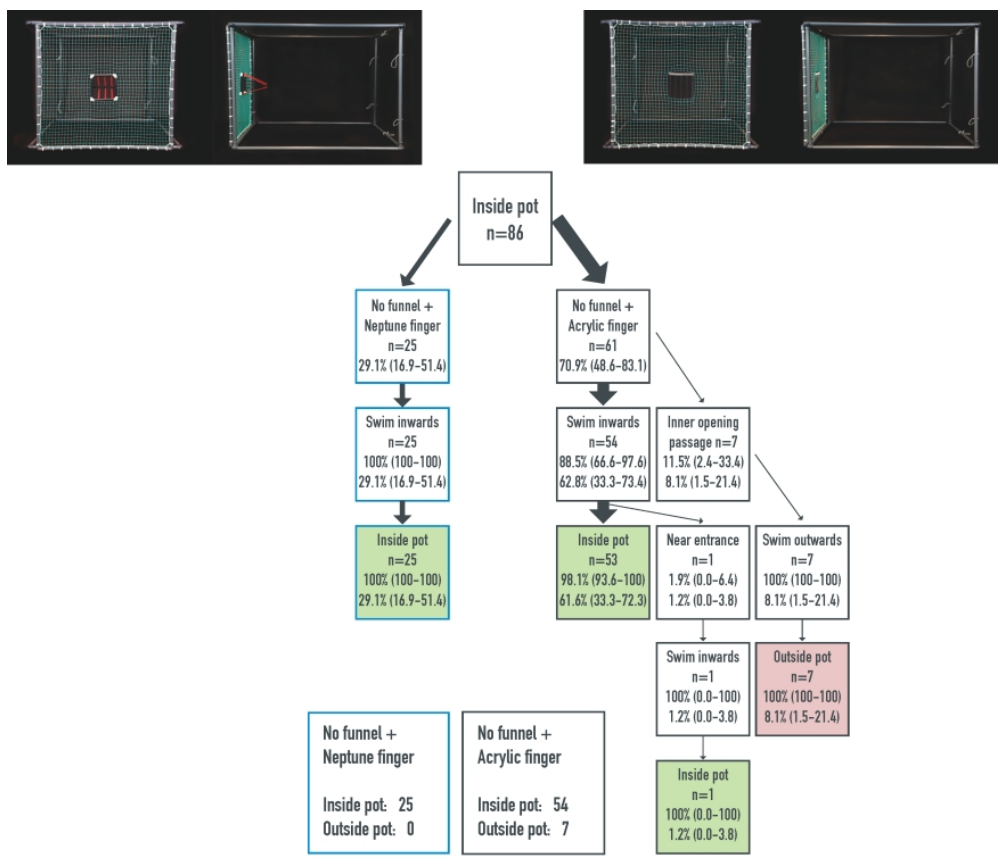

Figure 15. Behavioural event-chain tree comparing the NoFun+AF entrance (Control) with the NoFun+NF entrance (Test) for interactions of cod with pot entrances starting inside. Each box represents an event type; the first line = event type name; the second line = number of times this event was observed at this point in the event chain; the third line = the marginal probabilities (MP) related to the total number of interactions; the last line $=$ the conditional probabilities $(\mathrm{CP})$ related to the number of interactions in the parent link (the link above a respective link). Confidence intervals are based on 1000 bootstrap iterations. 


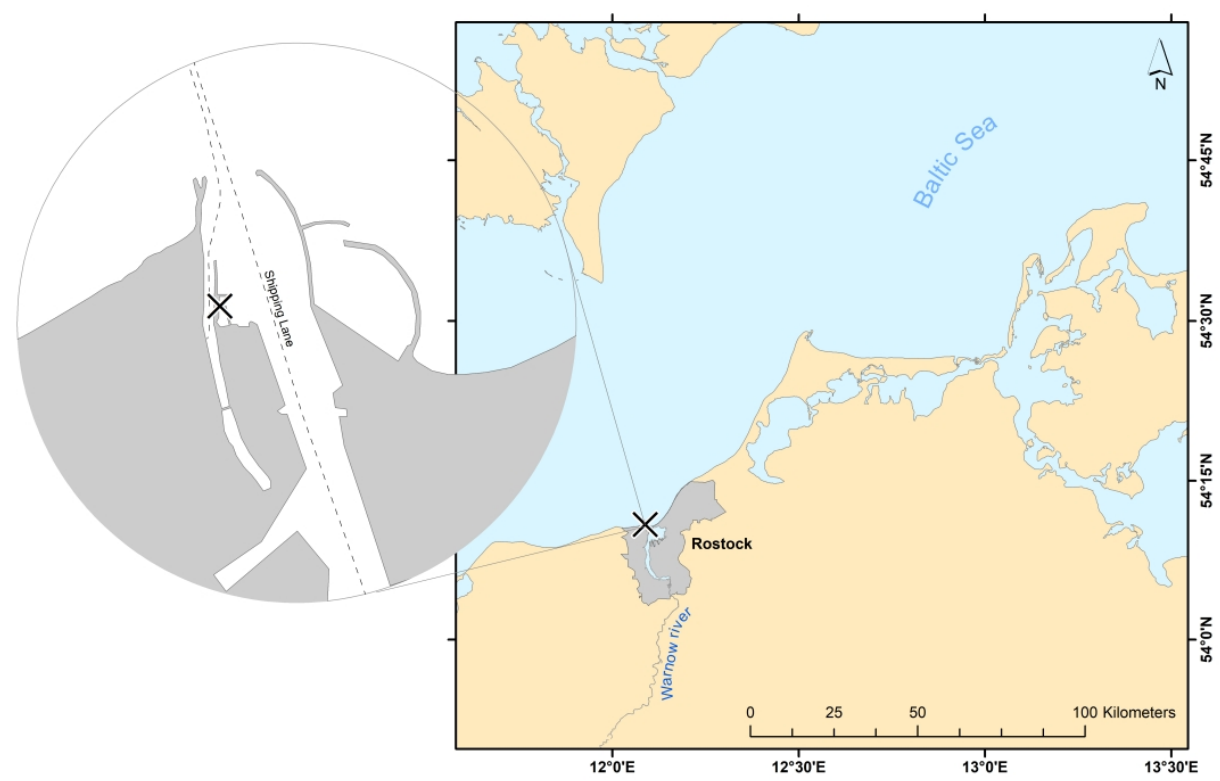

Figure appendix 1. Experiment location in the sporting marina Rostock-Warnemünde, Germany. 


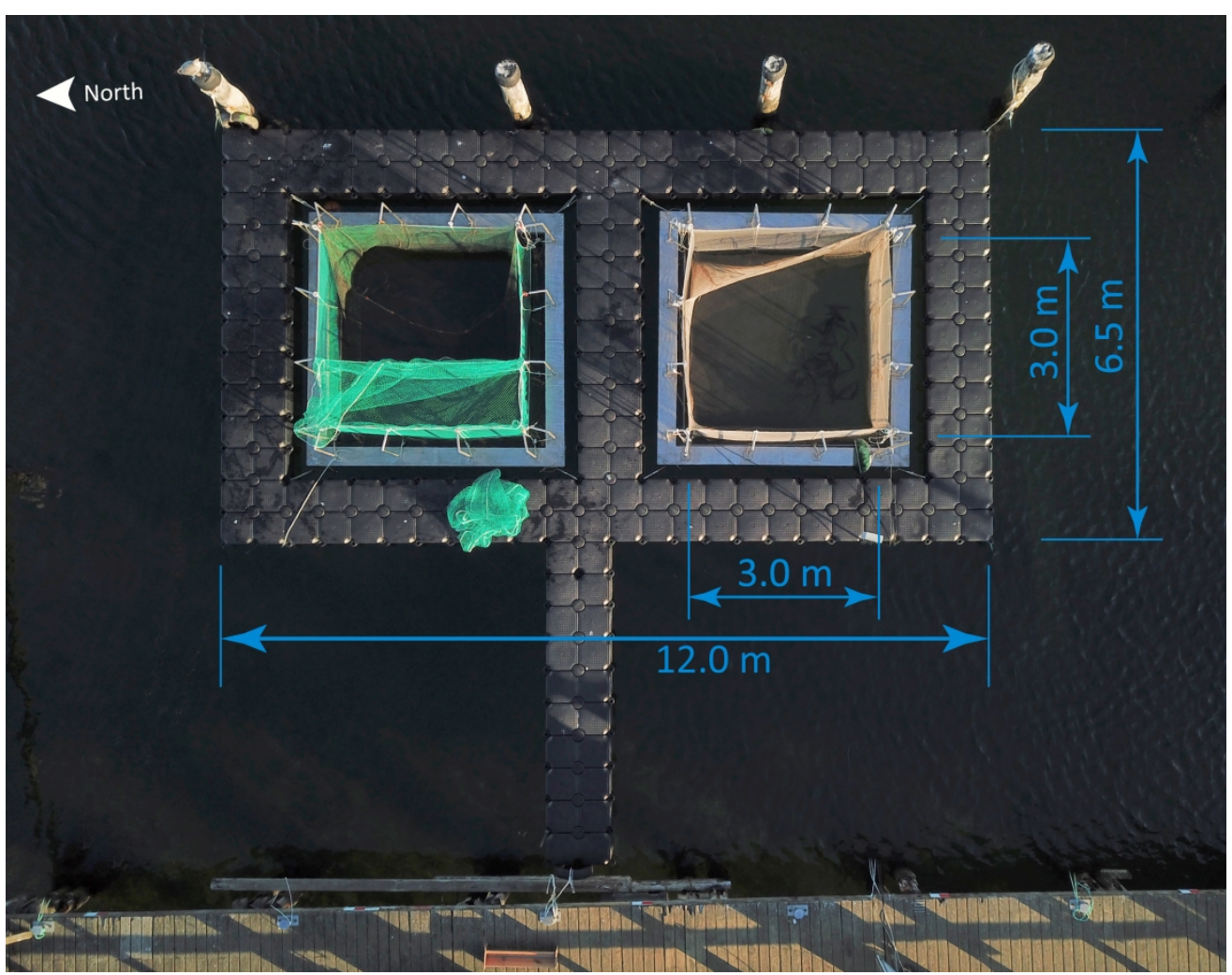

Figure appendix 2. Net pen facility in Rostock-Warnemünde, Germany. Aerial view. The right net pen (south) is the experimental net pen; the left (north) is the holding pen.

$$
1226 \times 961 \mathrm{~mm}(72 \times 72 \mathrm{DPI})
$$


Figure appendix 3. Schematic representation of the experiment's setup. An experimental pot with two exchangeable entrances is lowered into a $3 \times 3 \times 3 \mathrm{~m}$ net pen. Cod inside the pot are free to swim from one entrance to the other. For observation, an IR-camera system (one camera and one IR light in front of the entrance, one IR light inside the pot above the inner opening of the funnel), and two RFID antennae are mounted at each entrance. Note: Owing to technical difficulties, RFID data could not be used in the data analysis.

$768 \times 538 \mathrm{~mm}(72 \times 72 \mathrm{DPI})$ 


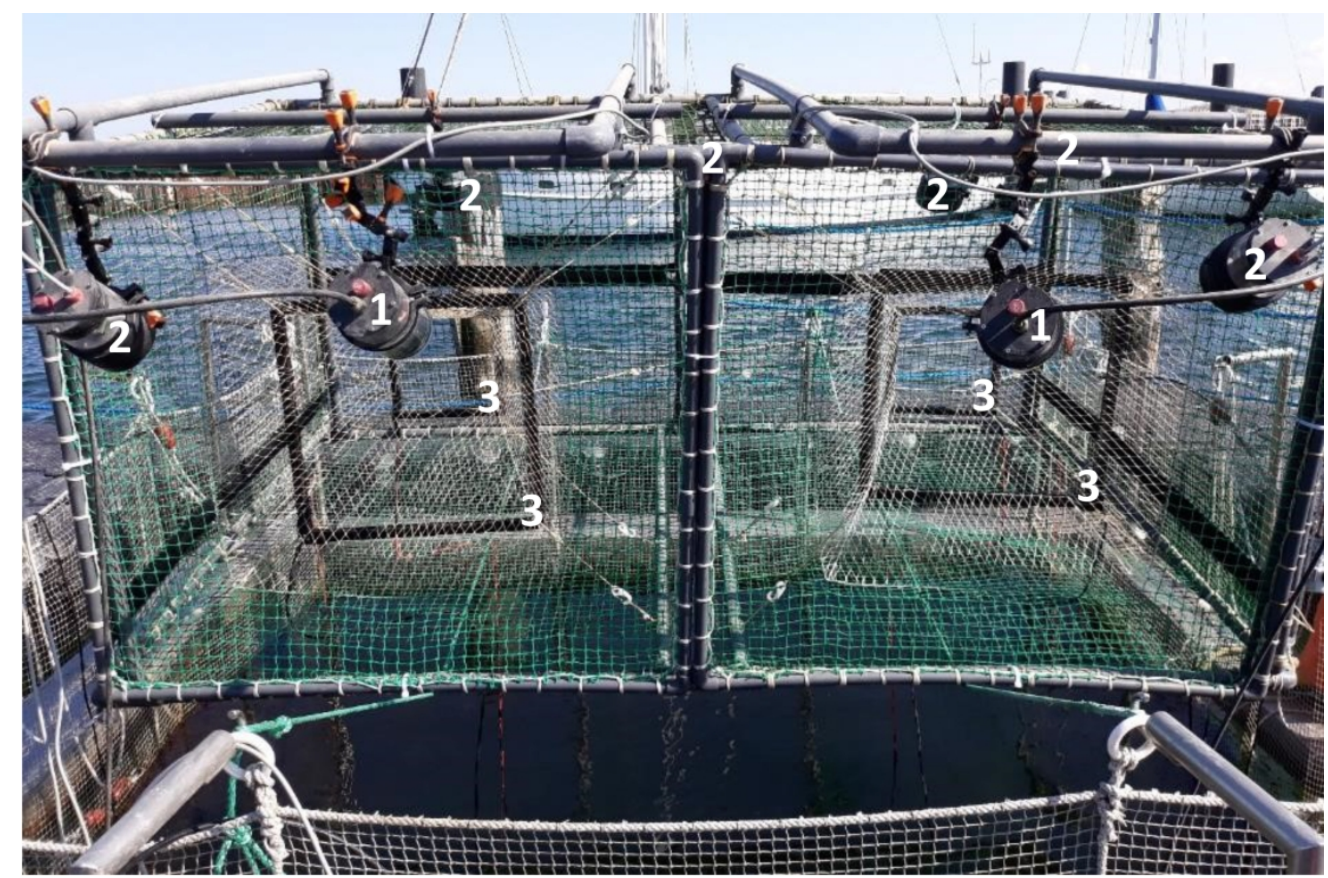

Figure appendix 4. Experimental pot with two exchangeable entrances. Two IR cameras (1) in front of each funnel entrance and two IR lights (2) on each entrance side (one inside above the funnel inner opening, the other outside next to the IR cameras). Black frames around funnels are RFID-antennas (3).

$224 \times 148 \mathrm{~mm}(300 \times 300 \mathrm{DPI})$ 


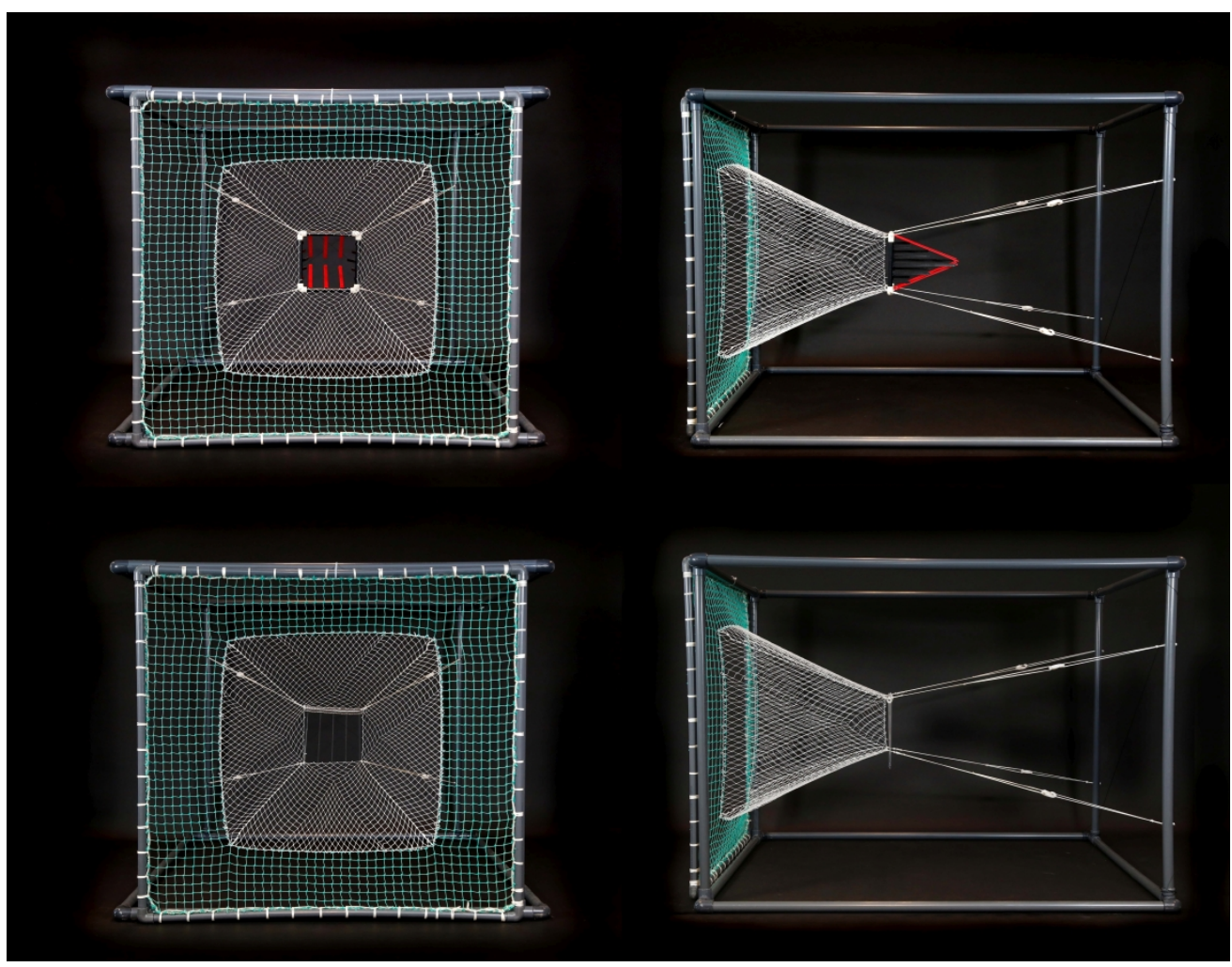

Figure appendix 5. Neptune fingers (NF, above) and acrylic fingers (AF, below) triggers attached to the Fun. Left front and right side views.

$2420 \times 1876 \mathrm{~mm}(72 \times 72$ DPI $)$ 